\title{
Counter-planning from the Kitchen: for a Feminist Critique of Type
}

\section{All happy families are alike; each unhappy family is unhappy in its own way ${ }^{1}$}

The Universal Exhibition that took place in London in 1851 is mostly remembered because of the Crystal Palace - a greenhouse turned monument, an abstract skeleton of cast iron and glass, a harbinger of modernity's obsession for flexibility and homogeneity. However, right in front of the Palace, British architect Henry Roberts built an unassuming two-floor prototype that was to become even more enduringly influential than its neighbour. ${ }^{2}$ The Model Houses for Families (Fig. 1) were presented at the exhibition as the simple aggregation of four units, but as the unit is repeatable Roberts put forward, ultimately, a Model for living that could - and would - trigger large scale applications.

Roberts' Model Houses are a good example of the way a small-scale architectural proposal can, in virtue of its repeatability, have an impact on the city itself, as the rather unassuming 1851 prototype would go on to influence in a determinant manner the way housing has been conceived, designed, and inhabited in the last 150 years. The link between production of type and production of city is not always a straightforward one, and yet, in this case, the Model Houses quite explicitly posit themselves as the key built ingredient of a future urban scenario. More interestingly, though, Robert did not content himself with the possibility to influence the city, but rather aimed to put forward an actual idea of society, and a specific form of

\footnotetext{
${ }^{1}$ This is the famous incipit of Leo Tolstoy's Anna Karenina (1873-78).

${ }^{2}$ Henry Roberts, The Dwellings of the Labouring Classes: Their Arrangement and Construction; with the Essentials of a Healthy Dwelling (London: Society for the Improvement of the Labouring Classes, 1867), 120-121.
} 
subjectivity. It is this link between city, type, and subjectivity that I will try to discuss in the following paragraphs.

With its grid of columns, the Crystal Palace embodied a spatial archetype based on evenness; the variety of millions of products originated all over the globe would be displayed within an equalizing framework where the only sense of direction and hierarchy was provided be the presence of a central nave and dome. No choreography would be imposed on the movement of the visitors of the Palace. On the contrary the aim of the Model Houses was to create hierarchies, orchestrate asymmetries, and ultimately enforce very specific behaviours. The flat is dominated by a living room that gives access to two small bedrooms, as well as a scullery. From the scullery, one can access a water closet and a larger bedroom. The plan spells out very clearly the type of family life it is designed for: mother and father will sleep in the main bedroom, from which the mother has easy access to the scullery, but also visual control of the living room. The children should be divided by gender - one room for boys, one for the girls. The family should not need to share anything with their neighbours, apart from a space to launder and dry larger items, therefore becoming truly 'nuclear' in its functioning.

Of course it would be impossible to claim that Roberts single-handedly 'invented' this spatial organization. After all, the success of the model is due to the simplicity with which it crystallizes the biological unit of reproduction: a man, a woman, their offspring. Throughout continental Europe, most urban dwellers lived in flats, which, with a growing concern for privacy, were organized roughly following this logic, as it is clear from handbooks from the mid-1700s. ${ }^{3}$ However, what Roberts did was to offer a repeatable, optimized layout. What he

\footnotetext{
${ }^{3}$ See for instance Charles-Étienne Briseux, Architecture moderne ou L'art de bien bâtir pour toutes sortes de personnes (Paris: Claude Jombert, 1728).
} 
designed is, therefore, not only a spatial type: it is a set of human types. Paraphrasing Tolstoy, Roberts' proposal suggested that all happy families should be alike. ${ }^{4}$

The Roberts model has become so diffused in the 150 years after its inception that today we barely question the fact that a flat should be partitioned in living room, kitchen, bathroom, master bedroom and children's bedrooms. The very nature of these spaces remains unchallenged since Roberts' time. The Model Houses for Families have become the most invisible and yet pervasive type: a spatial organization that is in fact a social diagram. Imagined in a specific historical and geographic context, Robert's diagram has gone on to become a totalizing apparatus that can now be found all over the world, enforcing a form of life that very often is at odds with the actual needs of the inhabitants. The ubiquitous repetition of this diagram should raise some questions; in fact, we could say that the nuclear family apartment is at the basis of contemporary city-making not only in terms of sheer quantity, but also, and most importantly, as it produces the subjectivity of the contemporary city-dweller.

The basic question at the root of my inquiry is whether the correspondence of spatial diagram and social diagram is unavoidable, and if so, what kind of agency can we reclaim as architects and users. As I read type as a spatial organization independent of function, it is a question that can apply to any kind of building or space; however, I will discuss here only housing examples.

There are two reasons for this choice. On the one hand, I believe housing is the richest field within which we can develop such an inquiry, not only in terms of quantity, but also because it is the genre within which typological thinking has found its most widespread application.

\footnotetext{
${ }^{4}$ The construction of the average family is obviously a process that goes well beyond architecture as described by Jacques Donzelot in The Policing of Families (Baltimore: The Johns Hopkins University Press, 1997).
} 
Typological thinking has been applied to housing relatively late in comparison to its emergence in the debate over public buildings, probably because until the 1800 s the vast majority of houses were not built by architects. But in the mid-1800s architects started to focus on typological experimentation applied to the domestic sphere and the link between organization of space and organization of life on a large scale was already very well understood in Roberts' time.

On the other hand, such a critique of type does not only involve architectural concerns, but has also social and political implications. A critical trajectory which can offer interesting insights in detangling the relationship between spatial and social diagrams can be found in the writings of feminist thinkers who devoted their work to the analysis of the house as social apparatus. It is for this reason that I call this line of inquiry a 'feminist critique of type', inasmuch as it uses tools borrowed from feminist writers to rethink type as a tool for the construction of subjectivity. The specific feminist tradition I refer to coagulated around the "Wages for Housework" movement, when, in the 1970s, a group of American and Italian writers sought to rethink the house as political and economic battleground. ${ }^{5}$ A seminal text of this movement is the 1975 pamphlet Counter-planning from the Kitchen, in which Nicole Cox and Silvia Federici attacked the very idea of domesticity that portrays the home as a place of rest and intimacy. ${ }^{6}$ Cox and Federici read domestic space as a place of work, and, more specifically, of what Marx already termed 'reproductive labour'. ${ }^{7}$ Reproductive labour is the sum of all the efforts needed to make life possible, from childcare to elderly care to the constant emotional support of one's spouse. Reproductive labour has been posited in the last

\footnotetext{
${ }^{5}$ The seminal book for this intellectual genealogy remains Mariarosa Dalla Costa and Selma James, The Power of Women in the Subversion of the Community (Bristol: Falling Wall Press, 1972).

${ }^{6}$ Nicole Cox and Silvia Federici, Counter-Planning from the Kitchen. Wages for Housework: A Perspective on Capital and
the Left (New York: Falling Wall, 1975).

${ }^{7}$ Marx discusses simple reproduction in Capital, Volume 1, Chapter 23.
} 
three centuries as something separated from 'production'. By separating reproductive, or domestic, labour from 'real' waged labour, or production, this effort can go unseen, and therefore unpaid, and exploited: it becomes just the 'natural' destiny of the woman, almost a pleasure. $^{8}$

This artificial separation between women's 'labour of love' and men's waged work has been constructed through a number of institutions and cultural practices - from modern marriage to the myth of romantic love. However, architecture has played a particularly crucial role in the development of division between the 'productive' workplace and the 'non-productive' intimacy of the house. This division has happened through typological articulation and, more specifically, through the application of typological thinking to the production of housing.

There have been many examples in modern architecture of emancipatory models of housing inspired by feminist ideas, examples that have tried to escape the rigid gendering of domestic space arisen in modernity. In the US, Dolores Hayden published a counter-history of modern American architecture that remains a fundamental contribution to the field, titled The Grand Domestic Revolution: A History of Feminist Designs for American Homes, Neighbourhoods, and Cities..$^{9}$ A similar narrative is still to be retraced outside of the US, but actual examples are definitely present and worth discussing - from Margarete Schütte-Lihotzky's Frankfurt Kitchen to Eileen Grey's radical interiors and beyond. ${ }^{10}$ However it is not the objective of this essay to consider the empowering potential of alternative models - be they inspired by feminist ideas or not. ${ }^{11}$ My aim here is, rather, to use the tools that feminist thinkers such as

\footnotetext{
${ }^{8}$ A book that chronicles the process of construction of unwaged housework is Jeanne Boydston, Home and Work: Housework, Wages, and the Ideology of Labor in the Early Republic (Oxford: Oxford University Press, 1990).

${ }^{9}$ Dolores Hayden, The Grand Domestic Revolution: A History of Feminist Designs for American Homes, Neighbourhoods, and Cities (Cambridge, MA: The MIT Press, 1981).

${ }^{10}$ Interestingly, the most radical house for a single person designed by Gray was not intended for a woman, but rather for a man, her lover Jean Badovici. See Caroline Constant, Eileen Gray (London: Phaidon, 2000$), 215$. ${ }^{11}$ We have to underline the fact that it is not the sole domain of feminism to look for alternative models of living; in fact, radical responses have often come from architects who were not at all engaged with feminist agendas (and the opposite is also, sadly, true - that not all feminist designers are necessarily innovative). For
} 
Federici have developed to cast a different light on the conventional production of architecture. Paraphrasing a well-known saying of Manfredo Tafuri's, I believe there is no such thing as feminist architecture, just a feminist critique of architecture. ${ }^{12}$ So in the following pages, much as I would like to, I will not review radical experiments ${ }^{13}$ but, rather, look at what kind of domestic spaces we are producing, where we come from, and how - if at all - we are pushing the boundaries of convention. If it is a feminist debate, it is so inasmuch as it takes the issues of production and reproduction as key lenses to read ongoing dynamics.

In this sense the Roberts model, so 'banal' not to deserve more than a passing mention in most history books, becomes crucial not because of its originality, but because it represents perhaps the first conscious attempt at institutionalizing reproductive labour; while many working class women would not be stay-at-home housewives in 1851, Roberts imagines his 'Model' wife as a mother who spends her day managing the house. The presence of an independent kitchen and a water closet in the family flat was a great improvement on the poor living condition of the lower classes - and yet, this technological advancement, a luxury at the time, also chained the woman of the house to a specific role, and a solitary one at that. Gone were the times of female solidarity forged while cooking, washing, taking care of children, and working on various crafts: the housewife Roberts had in mind was alone in her self-contained unit.

The seemingly innocuous, even well-intentioned operation of optimization put forward by Roberts in his ideal plan is in fact a large-scale project for the enforcement of a specific

\footnotetext{
an interesting cross-section of case studies see Francisco González de Canales, Experiments with Life Itself: Radical Domestic Architectures between 1937 and 1959 (Barcelona: Actar, 2012).

12 Tafuri famously wrote that there is no such thing as an architecture of class, just a class critique of architecture; as I follow a feminist strand that sees women precisely as a class, I believe Tafuri's point applies well also to the present case. See Manfredo Tafuri, "Toward a Critique of Architectural Ideology", in K. Michael Hays (ed.) Architectural Theory Since 1968 (Cambridge, MA: The MIT Press, 1998), 32.

${ }^{13}$ It follows that I am going to leave out, on purpose, the great tradition of collective housing that goes from pioneering Soviet examples such as Moisei Ginzburg's Narkomfin to reformist prototypes like Sven Markelius' building on John Ericssongatan in Stockholm.
} 
subjectivity, enacted through the replication of one single possible type of happy family. Of course, by 'happy' family, what I really mean is socially acceptable - real happiness in the sense of intellectual and affective fulfilment is definitely not a concern in the larger scheme of things as projects like Roberts' are aimed at shaping people's habits, not at encouraging emancipation.In this context, the most archetypal figure linked to unhappiness is the spinster, the single woman who is cut out of the 'natural' happiness offered to those who serve reproduction. It is not surprising then that modernity has failed to come up with typological answers to the housing needs of the single female; when this subject has been addressed in the 1800 s and 1900 s, architects have usually resorted to the use of premodern models such as the monastery. ${ }^{14}$

And yet it is exactly the single woman who inspired one of the most radical living proposals of the last few decades: Pao I and II - Dwellings for the Tokyo Nomad Girl by Toyo Ito (1985-1989, Fig. 2 and 3). ${ }^{15}$ The first Pao prototype was designed by Ito as an installation commissioned by a department store and it focused on a set of custom-built furniture pieces loosely arranged in a simple transparent tent; Pao II was redesigned for an exhibition and it featured a more elaborate envelope and urban strategy. In both cases the Paos stand as the polar opposite of the Roberts model for several reasons - not last, the fact that they refuse to posit the house as a type, as a spatial diagram. In these temporary installations, Ito imagines a tent that parasites roofs of existing buildings sheltering its inhabitant, a single working woman represented in the 1985 photos of Pao I by a young Kazuyo Sejima. The Nomad Girl does not cook, she doesn't even eat in the house, as the city itself becomes her dining room,

\footnotetext{
${ }^{14}$ For instance, see the cloister-like Hotel for Women in Park Avenue by A. T. Stewart and John Kellum (1869), in P.V. Aureli, M. S. Giudici, M. Tattara, Like a Rolling Stone: Rethinking the Architecture of the Boarding House (Milan: Black Square, 2016).

${ }^{15}$ Pao I was designed in 1985 as an installation for the Seibu Department Store in Tokyo. In this first proposal, the tent is a very minimal round enclosure, and the design is focused mostly on the furniture - see Andrea Maffei (ed.), Toyo Ito: Works, Projects, Writings (Milan: Electa, 2001), 50-53. In 1989 Ito had the opportunity to exhibit again the installation in Brussels, and with this occasion he further explored the tent-envelope - this version of the installation is titled Pao II, op. cit., 80-83.
} 
her kitchen, her living room. She retreats to her tent only to find calm and solitude, to sleep, relax, and indulge in hedonistic moments such as putting on her make-up and storing nicely her designer clothes. The project is literally just a tent, and a collection of playful, light pieces Ito calls pre-furniture 'for styling', 'for intelligence' and 'for snacking'. ${ }^{16}$ Pao is a house that is radically devoid of any domestic labour: the Nomad Girl is the opposite of the housewife.

But, more interestingly, Pao is a house without a type, a generic enclosure, with no kitchen, no bathroom, and almost no architecture, just furniture. This project challenges all the categories we adhere to when we design a 'normal' dwelling. It blurs the difference between sofa and bed, living room and bedroom. It refuses to repropose the traditional kitchen and bathroom that have become the workplace and prison of the housewife. Moreover, Pao does not have the ambition to become a 'model': it is not intended for replication. While it does contain pieces of furniture that can be mass produced, the tent itself becomes an ad-hoc, almost piratical intervention that disturbs the existing city as a constant reminder of another way of living. Other Nomad Girls can perhaps buy the same furniture, but will need to arrange it in a way that is specific to their own needs, with no pre-set choreography of use, no typological blueprint.

The Roberts Model House, read in the light of a feminist critique of reproductive labour, makes quite explicit the way in which type has been used in the last centuries as a tool to produce specific subjects. Ito's Pao shows a rejection of this condition, challenging the user to reimagine their form of life.

Indeed, unhappy families seem to have, at least, the luxury of choice.

\footnotetext{
${ }^{16}$ See Andrea Maffei (ed.), op. cit.
} 
The contemporary production of housing is somewhat suspended between these two opposing paradigms: the replication of the Happy Family, and the search for a posttypological housing very often inspired by the same ideas of flexibility that informed Ito's Pao. It has become rather evident that the Roberts model is inadequate to host forms of living that are increasingly diverse; work and reproduction cannot be so clearly separated, and the nuclear family has changed, perhaps waned. However we still cling to many of the tropes crystallized by Roberts, including the characterization of different rooms by function. It is in this conjuncture that the last decade has seen a return of the discussion on type.

In his 1976 essay "The Third Typology" Anthony Vidler described the emergence of the discourse on type in three different historical contexts. ${ }^{17}$ If the 'first typology' arose during the Enlightenment and hinged on the idea that architecture imitates nature, the 'second typology' emerged after the industrial revolution "assimilated architecture to the world of machine production"18: Vidler referred, respectively, to the writings of Laugier and Le Corbusier as key examples. The 'third typology' was, on the other hand, a term Vidler used to indicate the debate of his contemporaries, who, rather than finding a rationale outside of architecture, rooted typology in the very formal logic of the city. Aldo Rossi's work is here Vidler's main case study.

Vidler's analysis remains perhaps one of the sharpest writings on type as, rather than trying to define what type is, he contextualized its instrumental meaning in crucial passages of the modern debate. The three moments highlighted by Vidler all share, beyond their differences, a few similarities: they are moments in which a new social class needs to be addressed, and in which architecture struggles to redefine itself as a discipline. These two conditions might or might not be related, but the fact remains that faced with the rise of, respectively, the

\footnotetext{
${ }^{17}$ Anthony Vidler, “The Third Typology”, in Oppositions 7 (Winter 1977): 1-4. ${ }^{18}$ Ibid.
} 
bourgeoisie, the industrial proletariat, and the white collar worker, the first three 'typologies' have offered architects an intellectual tool to deal with a shifting mandate.

We might very well ask ourselves, then, why today the discourse on type seems relevant again, and why it is so urgent to address it when it comes to housing, which is the genre that before any other is asked to accommodate - and shape - new subjects.

In the following paragraphs I will therefore try to put forward a few conjectures on the predicament of type today, looking at the recent housing production of three countries with an established architectural discourse and an ongoing production of high-quality housing: Switzerland, the Netherlands, and Japan. The reason for this choice is simple. While these three contexts rank high today in terms of GDP per capita and Development Index, their economic and technological growth has not been a gradual process. If other countries - for instance France, Germany, the US - already faced the challenges of industrialization as early as the beginning of the $1800 \mathrm{~s}$, the chosen contexts have been largely agrarian regions until the early 1900s. In all three cases social and technological modernization happened very fast, erasing traditional culture and imposing on architects the heavy mandate to 're-educate' the new citizens within few generations. I believe that this pressure-cooker condition makes their architectural history particularly easy to read as transitions that have taken centuries in France, Germany, and the US here happened in few decades. The passage from vernacular domestic space to designed and mass-produced housing has been very rapid, almost brutal; again, we could say that the same has happened in other countries, from Eastern Europe to South America. However, what makes Switzerland, the Netherlands and Japan special are other two facts. First, all three contexts developed a sophisticated design culture; and secondly, the state intervened in the making of housing models in a significant and lasting manner. By intervening I do not mean necessarily that the state engaged directly with the 
provision of housing, ${ }^{19}$ but, rather, that there was a high degree of awareness of the importance of architecture in shaping a new subjectivity, and that this awareness is shown by the degree in which the state has supported design education and architectural experimentation. ${ }^{20}$ I will mostly refer to the work of three specific offices - Christian Kerez, MVRDV and SANAA ${ }^{21}$ - so as to make the inquiry more specific, and enable comparisons. They are all offices whose production embraces a variety of genres, not only housing, and they are all offices which strive to produce architecture that is not only functional but also conceptually and aesthetically interesting. The intention is to read through their work a possibility to rethink the strategic role of type in the shaping of our forms of life. I organized the discussion around three main topics: the role of the room, the dialectic of night spaces and day spaces, and the relationship between served and servant spaces. In all three cases I will briefly discuss historical models relevant to the respective contexts in order to frame the key design issues at stake.

\section{Rooms: We could be Nomads in our own Home}

Until a little over a century ago, Switzerland, the Netherlands and Japan were rural countries. Most households lived and worked under one roof. A standard vernacular mountain house in

\footnotetext{
${ }^{19}$ For instance, in terms of sheer quantity of social housing Britain, France, Germany, and Italy are all more significant contexts; what we are after here is not the actual built matter, but rather the development of new models.

${ }^{20}$ On the issue of design quality as key factor in the Netherlands, see Matthew Cousins, Design Quality in New Housing: Learning from the Netherlands (New York: Taylor and Francis, 2009). Swiss housing policies are quite specific as the system is based on a controlled rental market, see Roderick J. Lawrence, "Switzerland", in Paul Balchin (ed.), Housing Policies in Europe (New York: Routledge, 1996), 36-50. On the state's impact on the transition to westernized housing in Japan see Ann Waswo, Housing in Postwar Japan: A Social History (New York: Routledge, 2013).

${ }^{21}$ I refer here to SANAA as the office of partners Kazuyo Sejima and Ryue Nishizawa; however, the three projects that will be discussed are not always credited to SANAA in the relevant literature so when describing specific works I will keep to the name under which they are formally credited (ie Kazuyo Sejima Associates, or Office of Ryue Nishizawa)
} 
the Alps would typically present thick stone walls; its interior would be dominated by a large room to store hay and host animals, mostly cows. The rooms for human inhabitation and work would be smaller, and often subdivided in an enclosure for sleeping, one for cooking, and one for crafts and cheese production (Fig. 4). ${ }^{22}$

Similarly, the centre of the Dutch hallenhuis (hall-house, Fig.4) was a grain storage flanked by stables and closed at the back by very small living quarters. The use of the rooms could shift throughout the day and depending on the season. ${ }^{23}$ Flexibility of use was enabled by the lack of any fixed service and simplicity of furniture. Spaces would be inhabited depending on environmental concerns - what was warm, or dry, or humid, or cool, or light, in a specific moment. The same approach shaped the Japanese minka farmhouse (Fig. 4), in which the only fixed element was the hearth, surrounded by alcoves occupied in a variable manner according to gender hierarchies and seasonal comfort. ${ }^{24}$

These houses are in a sense pre-typological; they are spatially very simple. Their rooms do not yet represent a rigid diagram of life. Reproductive and productive labour would happen at the same time, in the same spaces. Women and men would by no means be equal, but the productive potential of women, at least, was never doubted. Even in the minka, which saw a strict separation of genders - to the point that men and women would not sleep together - the wife would have a key role as productive manager of the house. However, as we have seen, the modern apartment implies a much more strict division of roles within the household. This division of roles is enforced by the subdivision of the house in specific rooms. The room therefore becomes the typological device which enables the crystallization of the pre-modern,

\footnotetext{
${ }^{22}$ Based on author's own work in Ticino and Valais cantons.

${ }^{23}$ On the hallenhuis, see S. J. Fockema Andreae, E. H. Ter Kuile, M. D. Ozinga, Duizend Jaar Bouwen in Nederland (Amsterdam: Aller de Lange, 1948), 245-283.

${ }^{24}$ A fundamental English text on the subject of Japanese vernacular architecture is Teiji Itoh, Traditional Domestic Architecture of Japan (New York: Weatherhill, 1972).
} 
fluid mixture of production and reproduction into to a regimented, modern Happy Family. As Roberts teaches us, to each room in the house is attached a 'right' use, spelled out by its proportions and its infrastructure - heating available in specific places, light available in others, water confined to the water closet, cooking confined to a stove and separated from the main fireplace.

In a 2007 housing competition (Fig.5), ${ }^{25}$ Swiss architect Christian Kerez put forward an interesting way to react to the rigidity of the standard apartment. Although all the units respond to a similar brief - two or three bedrooms, a bathroom, a kitchen, a living room each one presents a different layout. Within the same perimeter, the apartments present a variety of spatial relationships and proportions. Depending on the shape and position of the enclosed spaces, that is to say the bedrooms and the bathroom, the remaining floor area gains a special character and unique relationship with the envelope: it becomes a single large open space spanning the whole length of the building, or it is split in two rooms connected by a short corridor, or it is shaped into a sequence of three niches with windows that open towards different vistas. The functional narrative of the individual rooms is not questioned; however, by pushing to the extreme the variety of formal arrangements, the architect encourage the user to (mis)use the different spaces in unforeseen combinations.

Much the same agenda could be attributed by MVRDV's project for Patio Houses in Ypenburg (1999, Fig. 6); ${ }^{26}$ a compact 1-story block hides, in this case, an extraordinary internal complexity. Units include a variable amount of patio space, as well as a standard series of services - kitchen, bathroom, bedrooms. While the single functions in themselves are treated fairly traditionally, the layout of each unit is different and exaggerates a specific

\footnotetext{
${ }^{25}$ See Christian Kerez 2000-2009: Basics on Architecture, El Croquis 145 (2009), 172, for the first phase of the competition for the Werkbund Wiesenfeld Residential Estate in Munich which is discussed comprehensively in 166-173.

${ }^{26}$ See Stacking and Layering: MVRDV 1997-2002, El Croquis 111 (2002), 130-139.
} 
feature: either the rooms are all the same size, or they are arranged as a long enfilade, or packaged in a central core, or dispersed in a constellation of circular enclosures.

In both Kerez's and MVRDV's cases the simplicity of the overall envelope underlines the fact that the complexity of the interior is a deliberate choice. On the other hand, in Ryue Nishizawa's Eda Apartments (2002, Fig. 7) ${ }^{27}$ the site condition dictates in part the fragmentation of the layout. Elevated above the site, the Eda Apartments are designed as a single horizontal building slab pierced by holes that offer different lighting conditions to each unit. Entrances are organized through staircases, and as most of them give access just to one flat the individuality of the apartments is further emphasized. Most of the living space is left unscripted, but due to the geometric constraints of accesses and light-wells the flats present strong formal characteristics that make each of them unique, such as elongated curved walls, or corner rooms with windows on two sides.

On the one hand we could say that these proposals expand the existing catalogue of established apartment 'types': after all, they accept a conventional set of purpose-made rooms as basic ingredients of the flat. On the other, the spatial variations they present are so extreme as to question the Roberts model. The Roberts model was ultimately a diagram of relationships, and not a formal example: but the formal experimentation presented by these cases pushes the diagram to a limit where its agency is put in crisis. As the rooms present very unconventional shapes, they encourage the user to use them in different ways: to become nomads in our own houses.

The three offices might have arrived to similar conclusion, but they likely started from different concerns. Kerez's proposal seems to be a sophisticated formal and tectonic

\footnotetext{
${ }^{27}$ The project is credited to Office of Ryue Nishizawa. See SANAA: Kazuyo Sejima \& Ryue Nishizawa, 1998-2004, El Croquis 121-122 (2004): 340-247.
} 
experiment. Nishzawa seeks to mirror the complexity of the city with an idiosyncratic individual sphere. MVRDV, as in many of their housing projects, are looking for the expression of the time-honoured political and agonistic nature of the Netherlands as a place of differences.

Although the agendas that animated the three projects are not aligned, in each case the floorplans spell out the same typological - or, rather, anti-typological - conclusion. Evidently this is not a coincidence. These examples ultimately do share a common goal: the attempt to address an inhabitant that is not Roberts' nuclear family anymore. In doing so, they recreate some of the conditions that were to be found in vernacular houses before the typological development of the modern apartment: spaces can be interpreted following their environmental character, their views, their qualities - and not necessarily in virtue of their pre-set programme.

This attitude seems an interesting response to the contemporary way of living. We are less and less similar to Tolstoy's happy families, and closer to the Tokyo Nomad Girl, moving camp within our house. This shift highlights the fact that the artificial distinction between work and reproductive labour has collapsed. The home is not anymore the hallowed place of the reproduction of the family. At the same time, the work we undertake outside the home has now increasingly absorbed some of the characters of reproductive labour: its essentially social nature, its focus on service and interaction, its 'immaterial' quality. ${ }^{28}$ Reproductive labour is nowhere and everywhere in the city at once. The house becomes a city, the city a house.

\footnotetext{
${ }^{28}$ On the totalizing nature of post-fordist work and its political implications see Bifo Berardi, The Soul at Work (Los Angeles: Semiotext(e), 2009).
} 
What we can learn from the way in which Kerez, MVRDV and Nishizawa mobilize form to challenge routines is that that type is not condemned necessarily to becoming a rigid choreography of life. In its radical, disruptive presence, the form of these dwelling seems to introduce an interesting friction in the automatic production of the standard Happy Family.

\section{Day spaces vs night spaces: The house is a bedroom}

The subdivision of the house into rooms with specific names is a relatively recent thing. In particular, the rigid polarization between a 'public' living room and a 'private' bedroom is definitely a recent construction as premodern houses offer us examples of layered systems of thresholds that manage different social spheres in more complex and flexible ways. ${ }^{29}$

The living room and its antecedents, the parlour and the drawing room, are the perhaps the types of room that emerged more recently as the 'largest' room in the house was by and large a multifunctional, undefined enclosure in premodern times. It is the bedroom on the contrary that is the first specific room to be delineated as separate from the rest of the house: we have proof of the fact that the conscious planning of the bedroom as a specific room emerged in Europe as early as the 13 th century. ${ }^{30}$ The history of European furniture shows us how the bed emerges as the first stable, elaborate piece of furniture present in medieval homes.

For instance, in an example of alpine inn dating from the 1700s (Fig. 8), the lower access level is a large unscripted space for trade and storage that serves as the local meeting house

\footnotetext{
${ }^{29}$ For instance, the French word for apartment, appartement, was used to indicate a set of rooms within a well-off household; the appartement could contain an antichambre, a chambre, and a cabinet - one could sleep, eat, or socialize in either of them and usually did, according to the time of day and the selection of companions. See J. F. Blondel, Cours d'architecture vol. 4, 207-210.

${ }^{30}$ See Mary Eden, Richard Carrington, The Philosophy of the Bed (London: Hutchinson, 1961).
} 
and tavern, while the upper floor hosts the owner's family. There are three small bedrooms, yet no living room proper said. ${ }^{31}$ Cooking, crafts and social interaction all take place in the same space. Similarly, in a Dutch canal house of the 1700s (Fig. 8) the bedrooms would be found on the first and second floor; on the ground floor, the front of the house would be dedicated to trade and public life, while the back is an extended kitchen-living room inhabited by women, servants and kids. ${ }^{32}$ The canal house layout is close to its Japanese contemporary, the Edo-period machiya ${ }^{33}$ (Fig. 8) which is also articulated following a front of house, back of house logic. As the front of house deals with the public, and the back with the family, production starts to be distinguished from reproduction; the woman is pushed to the back of the house or the top floor. Only when the public element will be expelled from the house in its entirety the parlour, then living room, will be needed to mediate with visitors. ${ }^{34}$

These three cases can be considered middle-class in relationship to their respective context: houses of small-scale merchants. In the two western cases we can see that while the living room had not yet appeared as necessary element, the bedroom was already a clearly defined space. The bed was not necessarily associated with sleep, sex, and illness, so it was acceptable for people to share the same bed, a piece of furniture associated with warmth, comfort and protection and used throughout the day as multifunctional space.

\footnotetext{
${ }^{31}$ On the constructive logic of alpine domestic architecture, see Giovanni Simonis, Costruire sulle Alpi (Verbania: Tarara, 2005).

${ }^{32}$ See chapter 1, "Domestic Pleasures", of Freek Schmidt, Passion and Control: Dutch Architectural Culture of the $18^{\text {th }}$ century (London: Ashgate, 2015).

${ }^{33}$ See Karin Löfgren, Machiya: History and Architecture of the Kyoto Town House (Stockholm: KTH Royal Institute of Technology, 2003).

${ }^{34}$ An interesting discussion of the emergence of the parlour in Britain can be found in Thad Logan, The Victorian Parlour: A cultural Study (Cambridge: Cambridge University Press, 2001).
} 
On the contrary, in premodern Japan the bed was a set of movable futons; because of the flexibility of this system, the machiya does not need a bed-room as such. In the 1900s, western-style beds became increasingly popular. With them, the ideology of 'conjugal love' emerged as social lubricant needed to enforce a specific model of family life. Arguably, the role of women in Japanese society had always been a subordinated one; after all, in the minka the women of the household would sleep close to the irori hearth rather than on the raised tatami platforms with their husbands. This condition, however, allowed for strong social bonds of solidarity between women of different generations, a solidarity that was severed by the introduction of a western model that subjected women to filter all their interactions through the husband-wife relationship.

What happened in Japan within decades was a condensed version of what had happened in Western Europe in four centuries. The invention of marital love was quintessential to mask the hard reality: that the woman was becoming an unwaged worker in the house. Marital love shrouded this condition in the rhetoric of voluntary care of one's loved ones. ${ }^{35}$

The architectural 'invention' of the bedroom as the ultimate place of privacy, as the locus of marital love, was quintessential to this narrative. However, in recent years working and living habits have changed, and the use of the bedroom cannot be confined to a solely 'reproductive' role. Thanks to portable devices and internet connection, we perform more and more work in the house, writing, reading, and using social media. This turns the bedroom into a living room, something that had already been very clear in the 1970 s when architects such as Ettore Sottsass and Archizoom posited the bed as a place of socialization, work and

\footnotetext{
${ }^{35}$ The construction of the Japanese housewife is analysed in Chizuko Ueno, "Genesis of the Urban Housewife", in Japan Quarterly 34 (April-June 1987), 132-142.
} 
entertainment. ${ }^{36}$ It is therefore not surprising if in the recent work of Kerez, MVRDV and SANAA we find a number of projects that blur the distinction between day spaces and night spaces. For instance, in Kerez's Apartment House on Forsterstrasse in Zurich (1999-2003, Fig. 9) ${ }^{37}$ the layout is conceived as a fluid interior rhythmed by the loadbearing structure; the rooms are not imagined as strictly partitioned boxes, but rather as a sequence of spaces within which it is up to the user to establish a hierarchy of public and private. In Copenhagen, MVRDV converted a silo into housing (Frøsilo, 2005, Fig. 10) ${ }^{38}$ designing open-space apartments in which the bedrooms are separated from the living room with thin partitions and furniture; in fact, the flats appear as generous balconies cantilevering out of the silo structure, liberated from the conventional subdivision into small rooms. Even more radically, partitions disappear altogether in Kazuyo Sejima's Okurayama Apartments (2008, Fig. 11), ${ }^{39}$ where each unit is a stacking of one-room spaces articulated through a simple curving of the floorplan in order to allow for variety and visual privacy.

Beyond their different working methods, Kerez, MVRDV and SANAA all experimented with projects that blur thresholds and functional zoning. In all these three cases, at first glance it seems like the whole house has become a big living room. However, I would actually say that the whole house has rather become a bedroom. The tendency to receive guests in one's house has almost disappeared in big cities. The number of members of the average household is also shrinking, meaning that the living room is less and less public. In fact, the size of the living

\footnotetext{
${ }^{36}$ On Sottsass' beds, see Ronald Labaco, Dennis Doordan (eds), Ettore Sottsass: Architect and Designer (Los Angeles: Merrell Publishers, 2006), 35.

${ }^{37}$ See Christian Kerez 2000-2009: Basics on Architecture, El Croquis 145 (2009), 72-91.

${ }^{38}$ Ilka and Andreas Ruby (eds.), MVRDV: Buildings (Rotterdam: NAi 010 Publishers, 2015), 202-211.

${ }^{39}$ The project is credited to Kazuyo Sejima \& Associates. See SANAA: Kazuyo Sejima \& Ryue Nishizawa, 2004-2008, El Croquis 139 (2008), 260-267.
} 
room has been steadily decreasing in the standard apartment in developed countries. ${ }^{40}$ The living, even devoid of a hospitality role, has held its place as the largest room in the house in the last few decades thanks to the presence of the tv. Now that the tv has almost exited the house we might well imagine that the living room could shrink or even disappear, allowing for the appearance of different systems of organization: fluid enfilades of bedrooms, aggregation of individual cells, unscripted sequences of spaces.

The reason why this process is interesting is that it uncovers the importance of the bedroom as a 'productive' place. The Roberts model had constructed the main bedroom of the house as a hidden enclosure; the importance of this enclosure was inversely proportional to its visibility, as, by hosting sleep and sex, this room became the very place of the reproduction of the workforce. Already in the Roberts model, the bed was far from being solely a place of intimacy removed from the realm of production: in fact, it became the prerequisite for any kind of production to take place. Workers need to sleep and regain energy in order to perform the next day so the role of rest is quintessential to any productive system. The productive role of sex is also not to be overlooked; it is through sex that labour-force is produced in the form of new bodies, but also, it is through sex that workers can find a venting space to the frustrations of their day. This venting space is so needed that the sexual relationship between husband and wife was socially constructed in the 1900s as something in which the woman had no agency - something which in fact did not even require her full consent. ${ }^{41}$

It is therefore only thanks to the bedroom that production is, at all, possible - and consumption as well, as our bedrooms have kept on growing in size in order to allow us to

\footnotetext{
${ }^{40}$ There is still a lack of academic literature on the subject, but popular media have been discussing this phenomenon at least since 2000: http://articles.baltimoresun.com/2000-09-24/business/0009220018_1_living-room-formal-living-family-room (accessed February 22, 2017). For the Japanese context, see https:/www.ft.com/content/fec40338-a2d2-11e4-ac1c00144feab7de (accessed February 22, 2017).

${ }^{41}$ A fundamental text that tackles the role of sex in the issue of reproductive labour is Leopoldina Fortunati, The Arcane of Reproduction: Housework, Prostitution, Labour, and Capital, trans. Hilary Creek (Autonomedia: Williamsburg, 1995).
} 
hoard more and more possessions. The bedroom therefore becomes critical to feminist theory as it is the place where the modern woman is shaped as 'incubator' of the workforce, while also being encouraged to become a perfect consumer. ${ }^{42}$

But reproductive labour does not only take place in the bedroom, as it comprises a multiplicity of efforts needed for the physical and emotional maintenance of the life in the house. Moreover, today the task of maintaining and managing life is not anymore the sole domain of the housewife, but also, at different levels, of most post-industrial workers: we work by relating to each other, sharing knowledge, discussing, taking care of other people. We work by making our very affectivity productive. ${ }^{43}$

Managers, teachers, consultants, nurses, creative workers at large, and anybody who works in the service industry are all part of what has come to be termed as affective labour. ${ }^{44}$ Affective labour is labour that mobilizes man's social capacity - as such, we could say that reproductive labour is the most primitive kind of affective labour. To say that the house has become a bedroom means therefore to acknowledge the fact that reproductive labour has become the engine not only of the domestic condition, but of our post-fordist life at large.

The three case studies in Zurich, Copenhagen, and Tokyo, show how there have been recent architectural experiments that attempt to reject typological thinking applied to housing, in favour of a more entropic, free flowing understanding of space. However, if we define type as a spatial organization that shapes a specific subject, we can also see how this 'non-type' is ultimately a type. Traditional apartments address the nuclear family and the rigid division of

\footnotetext{
${ }^{42}$ Marketing research and economic analyses on the subject abund; a useful collection of texts can be found in Miriam Catterall, Pauline Maclaran, Lorna Stevens (eds.), Marketing and Feminism (Oxon: Routledge, 2000).

${ }^{43}$ All of one's subjectivity is made productive in a post-industrial context - for a portrait of this condition see Paolo Virno, $A$ Grammar of the Multitude, trans. Isabella Bertoletti, James Cascaito, Andrea Casson (Los Angeles: Semiotext(e), 2004).

${ }^{44}$ Perhaps the sharpest critique of the way in which we 'produce' by simply relating to each other can be found in Christian Marazzi, Capital and Affects: The Politics of the Language Economy, trans. Giuseppina Mecchia (Cambridge, MA: The MIT Press, 2011).
} 
productive waged work from reproductive labour. On the contrary, the fluid 'non-type' addresses a society in which diffused 'affective' labour has rather become the norm.

\section{Serving Spaces vs Served Spaces: Downstairs is the new Upstairs.}

If the dichotomy between night spaces and day spaces is a fundamental element of the modern apartment, an equally rigid hierarchy has been established between served spaces and serving spaces. The Roberts model makes this hierarchy very explicit by ejecting the cooking space from the main 'day' space into a small scullery attached to an equally small water closet. This very limited enclosure is the origin of the modern kitchen - that is to say, the place that more than any other has symbolized the instutionalization of domestic work.

As the kitchen needs fire and water, it is perhaps the first typologically defined space to appear in houses - the hearth is, after all, a primal figure in every culture. Neolithic dwellings, we could speculate, are extended kitchens of sorts, equipped with space to sleep. In ancient Greek culture, the word oikos, which is metonymically used for 'house', indicated in fact the corner of the house that hosted the only fixed hearth - the other rooms being heated with movable braziers - and, often a well or other source of water. ${ }^{45}$

Until the invention of complex chimney systems, not all dwellings in a multi-storey residential building could have an independent kitchen. The preparation of meals was, by necessity, a social chore, much more so than today. ${ }^{46}$ Due to the technical requirements of kitchens, buildings often presented just one kitchen, even when they hosted several households. This condition did not only apply to the countryside, where farms were inhabited

\footnotetext{
${ }^{45}$ Lisa C. Nevett, House and Society in the Ancient Greek World (Cambridge: Cambridge University Press, 1999).

${ }^{46}$ On the evolution of the kitchen see Susan Strasser, Never Done: A History of American Housework (New York: Pantheon Books, 1982), 33-66.
} 
by extended families, but also in cities where housing blocks could contain several units but just one main cooking space either on the ground floor, or in the attic.

If kitchen work was often shared, the same could be said for bathing. Again due to the effort needed to gather and heat clean water, bathhouses were very common in many premodern cultures including, most notably, Japan. However, it was also possible to clean oneself more summarily at home; due to the lack of plumbing, water had to be carried in buckets to the washbasin or tub and bathing could take place in any space of the house. The bathroom was only a set of pieces of furniture - from chamber pot to washbasin and ewer to bathtub which were often shared; their use did not necessarily imply the privacy we associate with them today. They could be moved from room to room in order to allow for different uses and were not attached to a specific space, although of course proximity to a source of water and heat simplified the logistics of bathing. ${ }^{47}$

If the kitchen was a fixed piece of infrastructure - the hearth - and the bathroom a movable piece of furniture, the technological advancements appeared from the 1800s onwards have drastically changed this condition, as exemplified by Roberts' model. With the invention of the cooking range and of optimized flue systems, every flat in a multi-storey building could be equipped with a scullery; demoted from its social, shared role, the single family kitchenscullery becomes a mere functional appendix of the emerging living room. This process of optimization would continue in the next century - most notably, the studies of Christine Frederick ${ }^{48}$ and Margarete Schütte-Lihotzky ${ }^{49}$ would highlight the need for an actual

\footnotetext{
${ }^{47}$ A recent, extremely thought-provoking work on the evolution of the bathroom is Barbara Penner's Bathroom (London: Reaktion Books, 2013).

${ }^{48}$ See Christine Frederick's own Household Engineering: Scientific Management in the Home (Chicago: American School of Home Economics, 1919).

${ }^{49}$ A good source of information on the Frankfurt Kitchen is Peter Noever, Margarete Schütte-Lihotzky, Die Frankfurter Küche von Margarete Schütte-Lihotzky : die Frankfurter Küche aus der Sammlung des MAK - Österreichisches Museum für Angewandte Kunst, Wien (Berlin: Ernst und Sohn, 1992).
} 
ergonomics of the kitchen in order to make the work of the housewife more efficient. While these studies were arguably motivated by emancipatory intentions, they helped to develop kitchens that have become increasingly rigid in their composition due to their technological complexity. The movement of the bodies in the space of the kitchen is scripted very precisely, the space minimized - the social role of what had once been an informal space is all but lost in the standardized kitchen we see in most housing developments of the post-war era. The kitchen has become just a cubicle in which the woman is supposed to do her duty as efficiently as possible, interacting very little with the other members of the household.

In fact, as it has been argued by the Wages for Housework movement, the development of optimized kitchens has exacerbated a rhetoric of frugality that puts squarely on the wife the task of making her husband's wage last. ${ }^{50}$ One of the most paradoxical and cruel tropes emerged in the early 1900 s tried to convince the workers that they should not campaign for better wages and working conditions, but rather force their wives to spend less and manage better their households.

It is through cultural leitmotivs such as that of frugality that capitalism drove a wedge between working class men and working class women: by typifying women as spendthrift in stark contrast with their wage earning husbands, or saintly mothers in stark contrast to their lazy, out-of-work husbands. So while the bedroom enforces 'marital love' as something women have to endure, therefore making honesty between spouses hard if not impossible, the kitchen drives men and wives apart by making money not a simple pragmatic concern, but an actual measure of one's worth as a worker or as a housewife. The characters of the good wife, the honest worker, the woman who doesn't enjoy sex, the violent husband, are present

\footnotetext{
${ }^{50}$ This issue is discussed in Counter-planning from the Kitchen; recently, Silvia Federici republished the text in a collection that contains several other essays pertinent to the present discussion: Revolution at Point Zero: Housework, Reproduction, and Feminist Struggle (Oakland: PkM Press, 2012).
} 
perhaps by default in any time and place; but they became full-blown stereotypes only when helped along by a rigid choreography of the family life in their apartment.

By replicating the Roberts model, typological thinking in architecture has somehow legitimated this process. As early as 1915, in the Netherlands the kitchen had lost its raison d'être as social core of the house, as exemplified by the plan of a unit in Michel De Klerk's Eigen Haard estate (Fig. 12) ${ }^{51}$ The disproportion between the small kitchen and the amount of (often unused) living room space becomes a clear diagram of the biased gendering of the house.

Even in ground-breaking projects such as the Swiss Siedlung Halen by Atelier 5 (Fig. 12), ${ }^{52}$ an otherwise progressive social agenda ends up failing to rethink the kitchen, which is conceived as a cubicle. Looking towards the back of the complex, the kitchen is separated from the living room by a staircase as if to highlight its secondary role.

But perhaps the most radical application of the Roberts model comes from the case study that is the most distant from Britain: in post-war Japan the introduction of the western flat was a full-fledged project of social engineering, often enabled by companies that would provide their sarari-men (waged workers) with housing meant to completely change traditional habits. ${ }^{53}$ No more nomadic sleeping, no more communal bathing, no more fluid spaces. The rooms in these complexes known as danchi (Fig. 12) are strategized in order to divide not only genders and ages, but also men's production, outside the house, from women's

\footnotetext{
${ }^{51}$ Manfred Bock, Sigrid Johannisse, Vladimir Stissi, Michel de Klerk Architect and Artist of the Amsterdam School 18841923 (Rotterdam: NAi Publishers 1997), 239-248.

52 Niklaus Morgethaler, Yukio Futagata, Atelier 5: Terrace Houses at Flamatt near Bern, Switzerland. 1957, 1960. Halen Housing Estate near Bern, Switzerland. 1961. Apartment in Brugg, Switzerlandd, 1970-71. (Tokyo: A.D.A. Edita, 1973).

${ }^{53}$ On the sarari-men subjectivity see Ezra Vogel, Japan's New Middle Class: The Salary Man and his Family in a Tokyo Suburb (Berkeley: University of California Press, 1971).
} 
reproduction. It is a series of compartments ready to be cleaned and maintained by just one person, the wife, the sole caretaker.

Looking at the shortcomings of these XX century examples, we might ask ourselves how contemporary architects confront the issue of the relationship between served spaces and 'serving' spaces - namely, kitchen and bathroom. One of the most striking responses to this issue is represented by Christian Kerez' 2005 Apartments with a Lake View (Fig. 13). ${ }^{54}$ The bathroom is designed as a solid enclosure, a monolithic room jutting out of the main body of the building. On the other hand the kitchen is positioned in the middle of an open space, almost like a piece of furniture floating freely in the living room. This solution represents a radical inversion of the premodern character of these two spaces: fixed kitchen, and movable bathroom.

The same thing happens in the Gifu Kitagata apartments designed by Kazuyo Sejima (2000, Fig. 15) ${ }^{55}$ the flats are conceived as a sequence of identical rooms, out of which one is equipped with kitchen appliances positioned in the middle of the space, while the bathroom becomes an enclosed, separated core.

With their 2002 Silodam building in Amsterdam (Fig. 14), ${ }^{56}$ MVRDV want to demonstrate how it is possible for a single development to hosts a large variety of different housing types. And yet, all these different units share a few key characters: they all present a service spine containing the fixed bathroom, while the kitchen counter is placed as a freestanding element in the middle of the main room.

\footnotetext{
${ }^{54}$ See Christian Kerez 2000-2009: Basics on Architecture, El Croquis 145 (2009), 160-165.

${ }^{55}$ Yuko Hasegawa, Kazuyo Sejima + Ryue Nishizawa: SANAA (Milan: Electa, 2006), 170-183.

${ }^{56}$ Ilka and Andreas Ruby (eds.), MVRDV: Buildings (Rotterdam: NAi 010 Publishers, 2015), 68-85.
} 
These three projects register a new way of looking at the kitchen, a shift that is perhaps needed if we want to re-evaluate the role of reproductive labour. In the last century technological advancement hasn't always contributed to the emancipation of reproductive labour; the rhetoric of the efficient kitchen tends towards the underappreciation of the effort needed to provide food. In fact, the modern kitchen generates new work for the housewife, which is isolated from her peers and tasked with the satisfaction of desires that are made increasingly more complex by the diffusion of consumer culture.

However, if technology hasn't helped women's work in the last century, it might well start to do it now. New systems of wireless powering, detachable induction surfaces, and diffused air vents are making the kitchen increasingly nomadic. This means that the kitchen does not need to be a cubicle anymore, but could rather become just a series of small objects, detachable, movable and safe to handle, so that all the members of the household can potentially use them - even kids. The kitchen walls are blurred and disappear. Not only eating but cooking as well becomes a social activity.

On the other hand, as the experiments of Kerez, MVRDV and SANAA show us, the bathroom has become not only the most fixed element in the house - because of plumbing and sewage - but also the most private, perhaps the only truly private space. As the bedroom becomes a place of work and the bathroom becomes fixed, almost monumentalized as embodiment of privacy, it is difficult to say which space is the servant, and which the served.

This subversion of traditional patterns is made possible, today, by emerging technologies. However, I believe that this form of typological experimentation is supported, but not driven, by these technologies. In fact, even at a time when wireless devices were still unthinkable, attempts to disrupt the hierarchies of the Roberts model have been infrequent, but by no means insignificant. On the topic of serving and served spaces, perhaps the most radical 
proposal was presented in a 1992 competition, Housing Barcelona, by Jan Neutelings, Alex Wall, and Xaveer de Geyter (Fig. 16) ${ }^{57}$ In their entry, the façades of a residential slab becomes as a wall of services, leaving the centre of the building free, unscripted. It is impossible to label these spaces as bedroom, bathroom, kitchen; intimacy and publicness can both find their place in this scheme, but their negotiation is entirely up to the users.

Ultimately, the proposal is a liberating and ironic inversion of the standard apartment: the servant becomes master, the upstairs downstairs, gender roles have to be rewritten.

As we have seen, the idea of type in housing has been instrumentalized to produce standardized subjects. However, as these last cases demonstrate, type is not a static concept, but rather an evolutionary process which contains within itself the constant possibility of reinterpretation, perversion, and change.

\section{Epilogue: We live in the office, work in our home. ${ }^{58}$}

As Andrea Branzi writes, architectural diagrams such as the bourgeois apartment have become increasingly inadequate vis-à-vis living and working conditions that cannot be explained anymore with traditional categories. The home is a workplace, and our workplace becomes the very locus of our social life; labour and love, necessity and ambition, collaboration and competition have become inextricably linked. ${ }^{59}$ But women have been in this condition for a long time, well before the emergence of post-fordism. This is my key reason to take a feminist standpoint in this enquiry.

\footnotetext{
${ }^{57}$ Featured in Gustau Gili Galfetti, Pisos piloto: células domésticas experimentales (Barcelona: Editorial Gustavo Gili, 1997), 40-42.

${ }^{58}$ This sentence is quoted from Andrea Branzi, Weak and Diffuse Modernity (Milan: Skira Editore, 2006), 62.

${ }^{59}$ For an in-depth analysis of contemporary subjectivity we refer here again to the seminal Paolo Virno, A Grammar of the Multitude, trans. Isabella Bertoletti, James Cascaito, Andrea Casson (Los Angeles: Semiotext(e), 2004).
} 
Women have been relentlessly shaped, measured, encouraged, pushed, and coerced by residential architecture in the age of type. It would stand to reason that women should be the first to reject typological thinking, as it has been such a successful tool for the construction of gender asymmetries. ${ }^{60}$ And indeed, female thinkers have done so, not only through their political writings, but also through architectural projects. Between 1987 and 1990, Kazuyo Sejima designed two houses she titled Platform I and II (Fig. 17); they are conceived as oneroom spaces open towards the landscape, although Platform I in fact contains a series of more typologically-defined rooms tucked away under the main space. The Platforms use light, industrial materials, their interior is not partitioned and their envelopes transparent, and in this they seem to continue Ito's Pao research; however, due to the complex and fragmented geometry of the exterior walls, the effect is strikingly different as the ever-protagonist tent of the Pao is here blurred and dissolved, leaving the roof to emerge as single guiding element. And in fact Sejima conceived her Platforms as the opposite, indeed as a critique, of Ito's Pao. ${ }^{61}$ Architecture is conceived here as a loose platform open for different uses: it is not a space for a family, but neither for a Nomad Girl, it is a space for nobody in particular. Perhaps, the platform is not even thought of as a space, but rather as a machine to be used for a while, and then left alone. The platform refuses to become a primitive hut, refuses to conform to any of the topoi of architecture as we know it. Sejima declared she "wanted to challenge the idea of architecture as a thing in which to wrap people up". ${ }^{2}$ Inhabitants use the platform rather than owning - or being owned - by it. ${ }^{63}$ In this case, Sejima's architecture

\footnotetext{
${ }^{60}$ We refer here again to Dolores Hayden, The Grand Domestic Revolution (Cambridge, MA: The MIT Press, 1981).

${ }^{61}$ Kazuyo Sejima + Ryue Nishizawa, El Croquis 77+99 (2001), 30-41.

62 “At first glance, some people might get the impression that my platform series emerged from Ito's Pao. But actually, the two couldn't be more fundamentally different. I wanted to challenge the notion of architecture as a thing in which to wrap people up. My response was to create a place through which people could pass quite frequently.” Kazuyo Sejjima in conversation with Koji Taki, in Kazuyo Sejima + Ryue Nishizawa, El Croquis 77+99 (2001), 25.

${ }^{63}$ The distinction between use and ownership is a fundamental topic if we want to rediscuss the juridical and political models that frame our way of seeing built space. A philosophical discussion of these terms can be found in Giorgio
} 
is conceived as pure infrastructure within which concepts such as production and reproduction, office and home, do not mean anything any longer. In fact, these two projects does not attempt to reform or rethink the domestic condition - they rejects domesticity toutcourt. Although they are simple, almost minimal projects, they are not diagrammatic: they do not indicate relationships, nor possible uses, nor choreographies. Platform II, in particular, is not a project that can be described through 'what it does', for it does nothing, it is not meant to perform in any specific way if not as an area of transit open to the interpretation of who will inhabit for a while. The two Platforms cannot be translated into a typological series, nor reduced to a spatial organization. Platforms are a thought-provoking response to a typological tradition that has often served as tool for the exploitation of women within the home. Sejima was not - at least explicitly - motivated by a feminist agenda, but she was interested in challenging the straitjacket of typological thinking.

Ultimately, I do not believe that there is such a thing as feminist architecture, but I do think that as architects we should learn from feminism how to pay attention to the construction of subjectivity. In this context, type cannot be used solely as a formal category, but should be seen as an experiential and political one. This critique could potentially be applied at all scales architects deal with, from the house to the construction of territorial 'types'.

We might then ask ourselves whether this critique implies, as in Sejima's Platforms, the need to abandon type as a tainted category. I hope that the examples I discussed in this text show that this is not the only solution, but that there are still opportunities to reappropriate typological thinking. It is, ultimately, a question of awareness: we, citizens, architects, are all at the same time victims and villains in this story. The domestic exploitation that once targeted women has escaped the house to invest the whole of the post-industrial world.

Agamben, The Highest Poverty: Monastic Rules and Form-of-Life, trans. Adam Kotsko (Stanford: Stanford University Press, 2013). 
Affective labour mobilizes the whole of the worker's life - it knows no 9-to-5, it makes leisure indistinguishable from production, and blackmails us into accepting poor wages in name of the 'love' of entrepreneurship and creativity. The hypostyle, uniform grid of the 'typical plan' has moved from the factory to the office and, finally, to our homes. We are left with the difficult choice between two scripted destinies, the Happy Family or the hipster loft. The city has become an infinite domestic interior, formally and socially, as the traditional boundaries between production and reproduction, home and workplace are increasingly blurred. As in the case of Henry Roberts' Model Houses, the relationship between city, type, and subjectivity becomes a complex field in which architects are challenged to intervene.

The examples we have seen tell us that ultimately we are destined, all of us, regardless of gender and class, to become housewives. And they also suggest us that, when that will happen, Le Corbusier's opposition between architecture and revolution, ${ }^{64}$ and my own opposition between type and revolution, would have no meaning: for the only possible revolution could only start again by counter-planning from our kitchens.

\footnotetext{
${ }^{64}$ Le Corbusier, Toward an Architecture, trans. John Goodman (Los Angeles: Getty Institute, 2007), 291.
} 


\section{IMAGES}

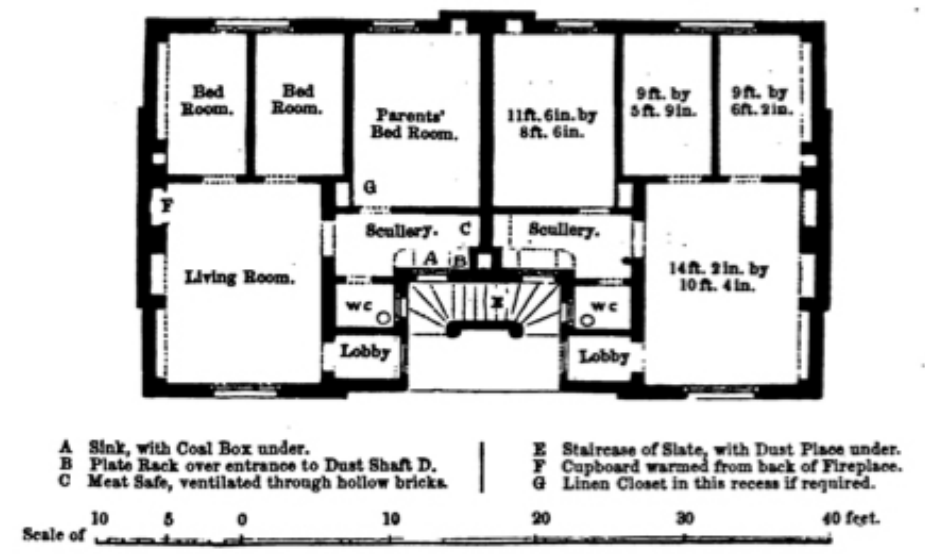

Fig. 1 Henry Roberts, Model Houses for Families, 1851.

Source: Henry Roberts, The Dwellings of the Labouring Classes: Their Arrangement and Construction; with the Essentials of a Healthy Dwelling (London: Society for the Improvement of the Labouring Classes, 1867). 

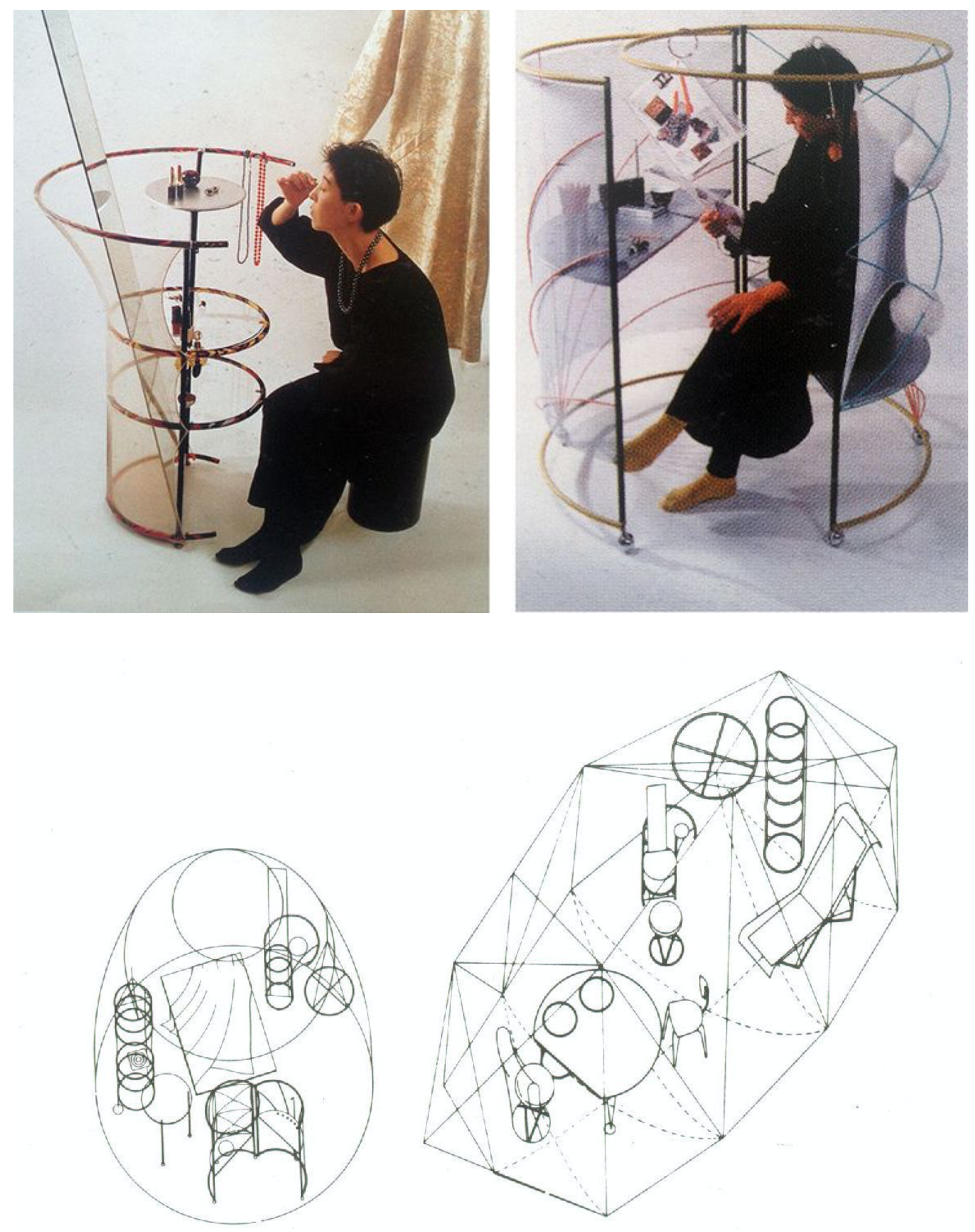

Fig. 2 Toyo Ito, Pao I (1985) \& Fig. 3 Toyo Ito, Pao I (1985, left) and Pao II (1989, right).

Source: Andrea Maffei (ed.), Toyo Ito: Works, Projects, Writings (Milan: Electa, 2001). 

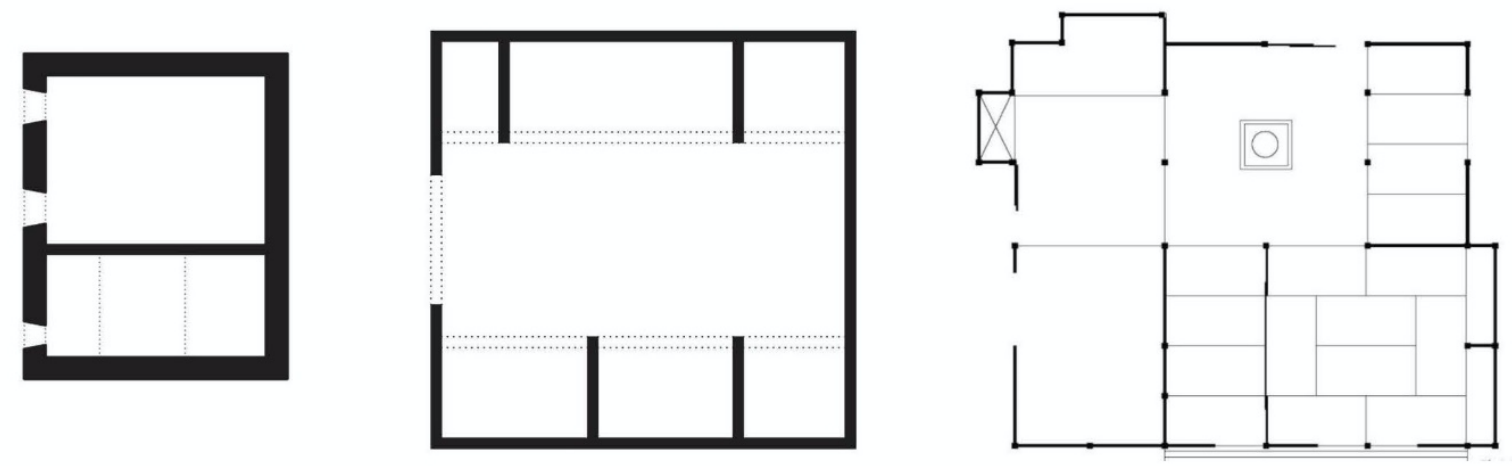

Fig. 4 Alpine stone hut, Dutch Hallenhuis, Japanese Minka

Redrawn by author. Minka courtesy of E. Hanae Bliah.
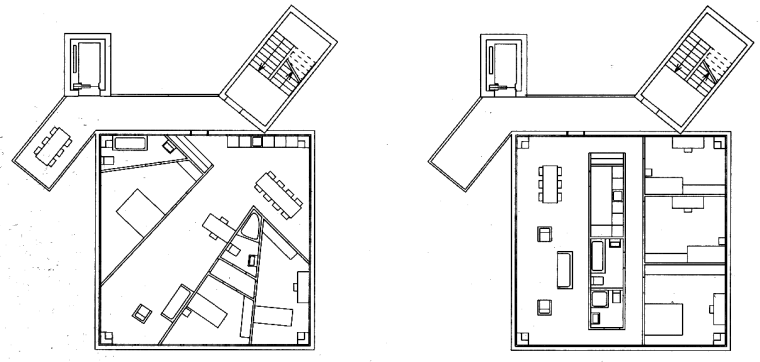

Planta segunda / Second floor plan

Planta quilta / F Fth floor plan
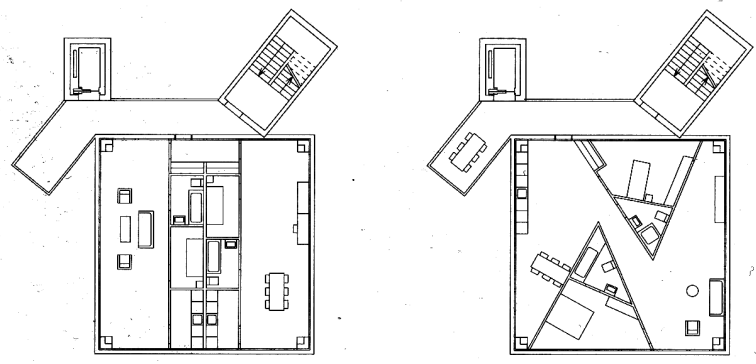

Planta primen / Frist floos plan

Planta cuarta / Fourth floor plan
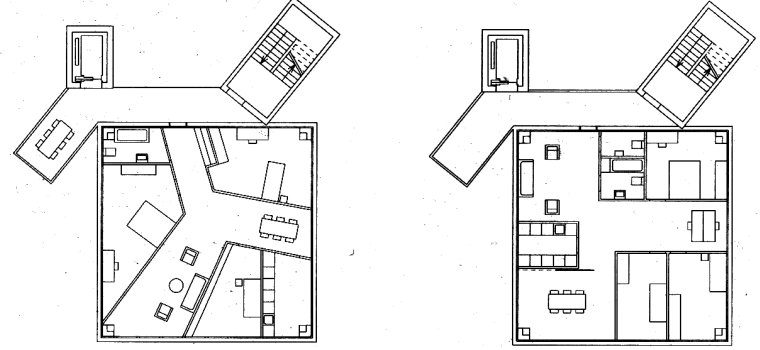

Planta bala / Ground flloor plan

O

Planta terceren/Thire floor plan

Fig. 5 Test plans for housing competition by Christian Kerez (2007). 
Source: Christian Kerez 2000-2009: Basics on Architecture, El Croquis 145 (2009), 172.

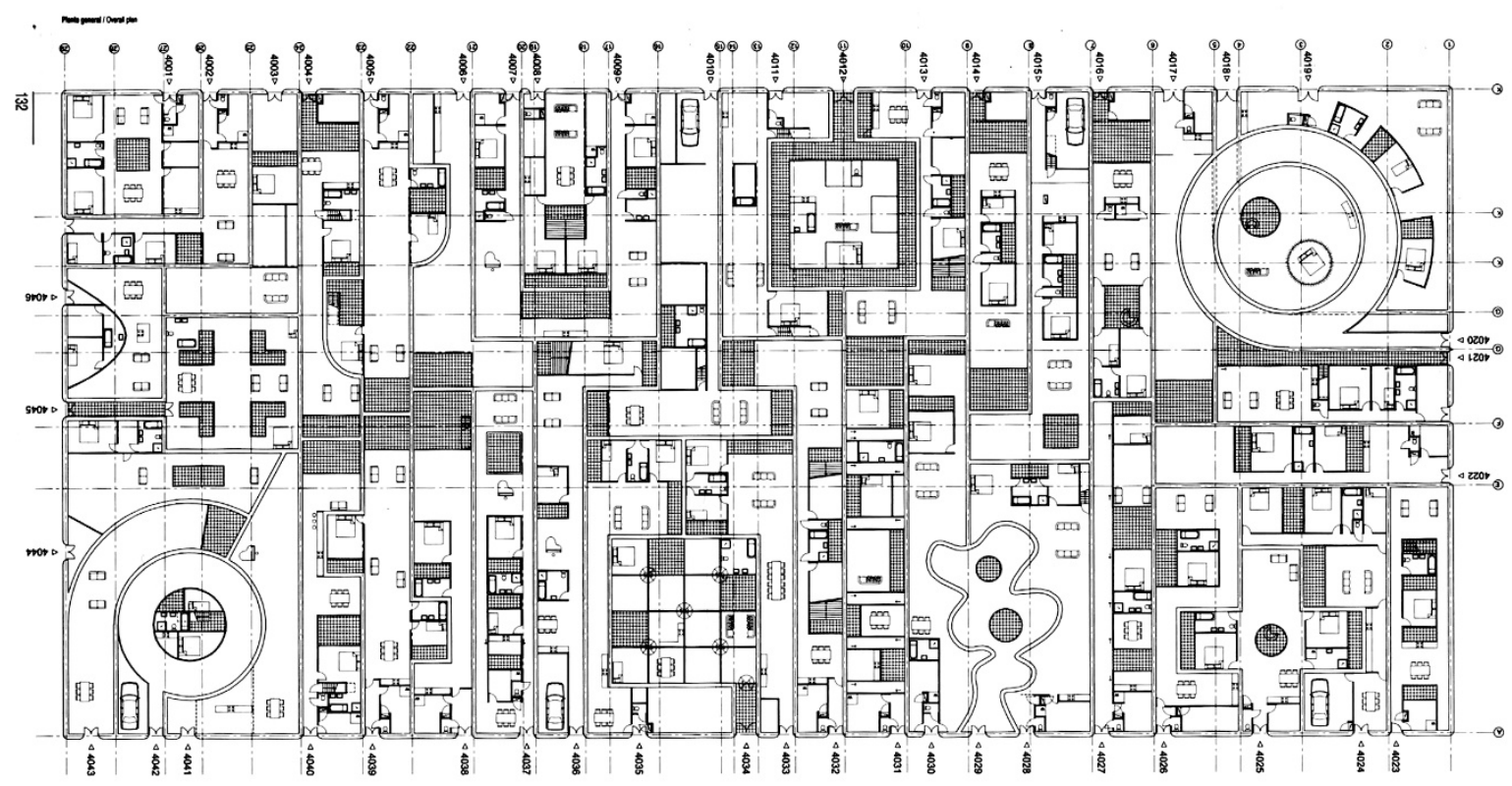

Fig. 6 MVRDV, Patio Houses in Ypenburg (1999).

Source: Stacking and Layering: MVRDV 1997-2002, El Croquis 111 (2002).

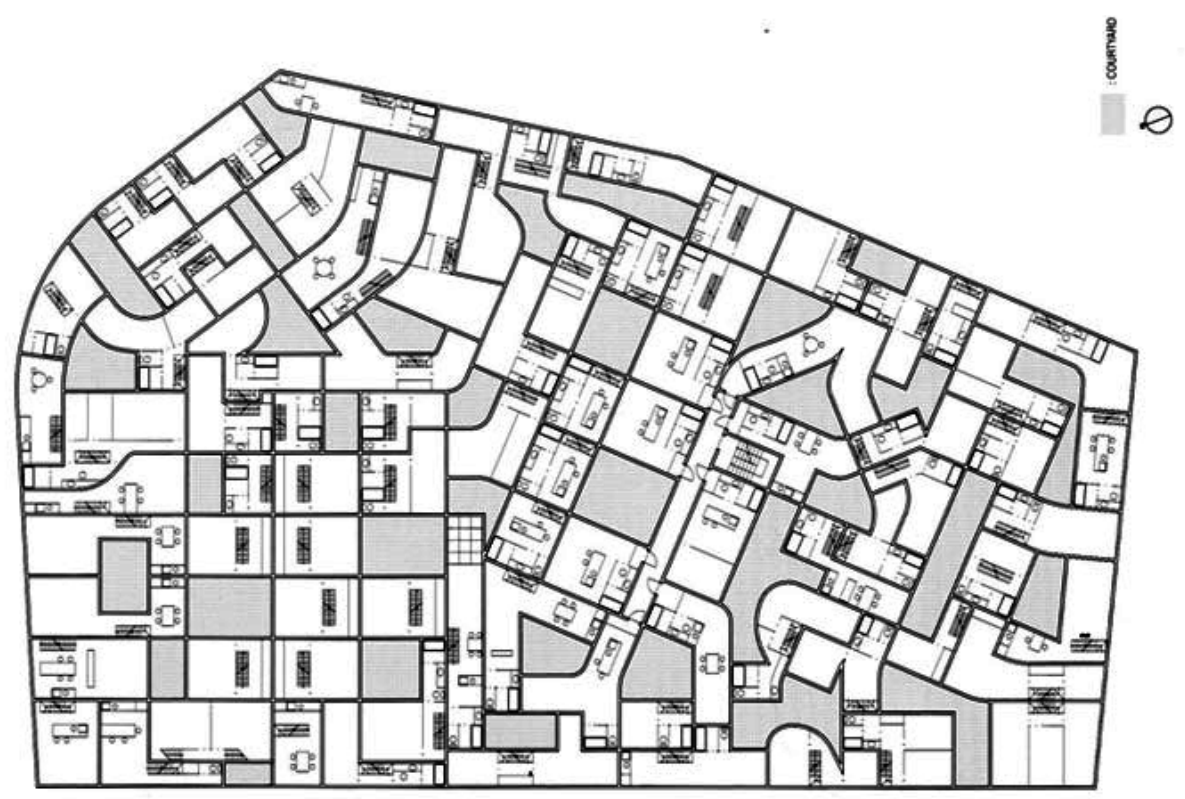

Fig. 7 Office of Ryue Nishizawa, Eda Apartments (2002).

Source: SANAA: Kazuyo Sejima \& Ryue Nishizawa, 1998-2004, El Croquis 121-122 (2004). 

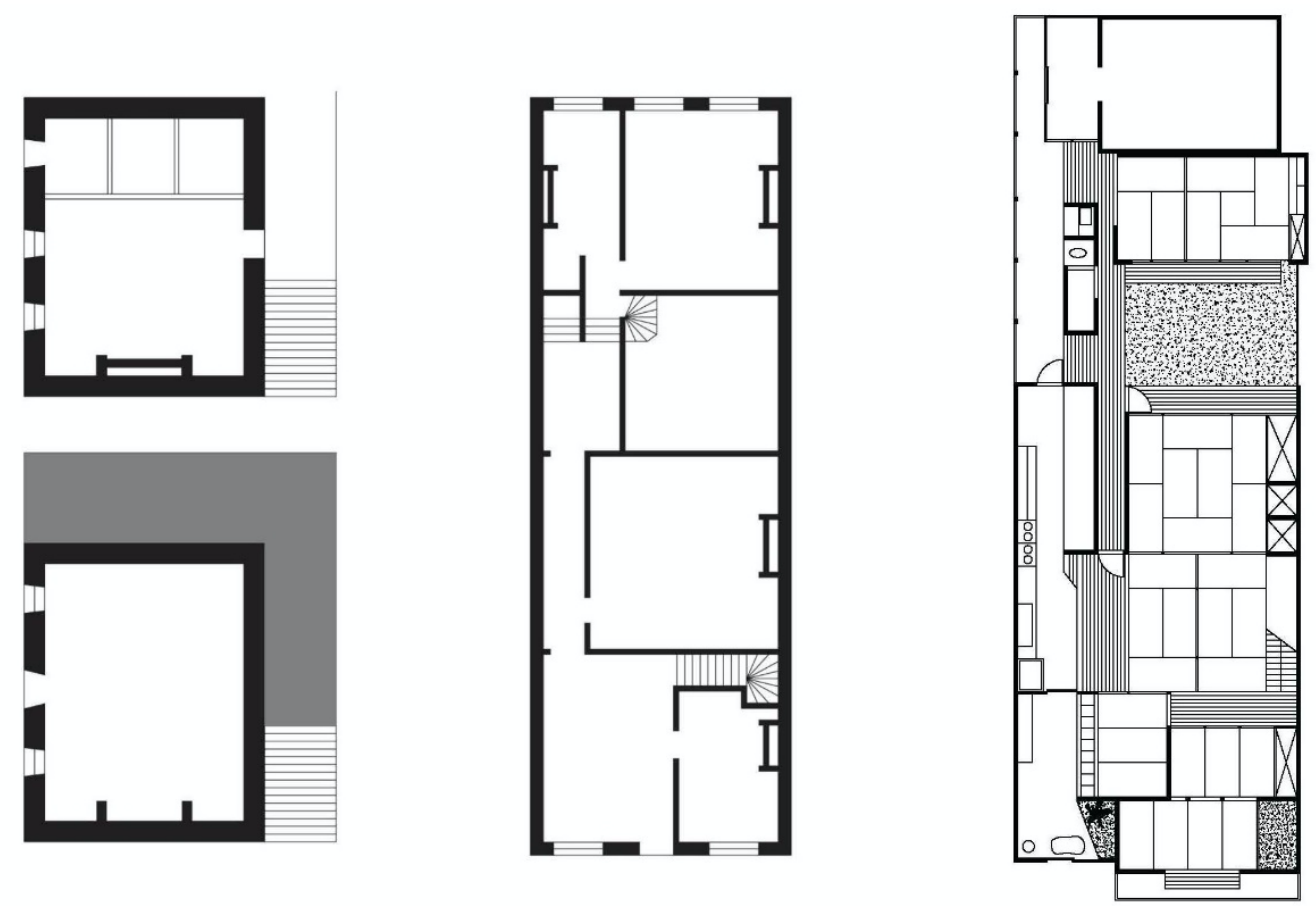

Fig. 8 Alpine inn on the Simplonpass, Dutch Canal House, Japanese Machiya Redrawn by author. Machiya courtesy of E. Hanae Bliah.

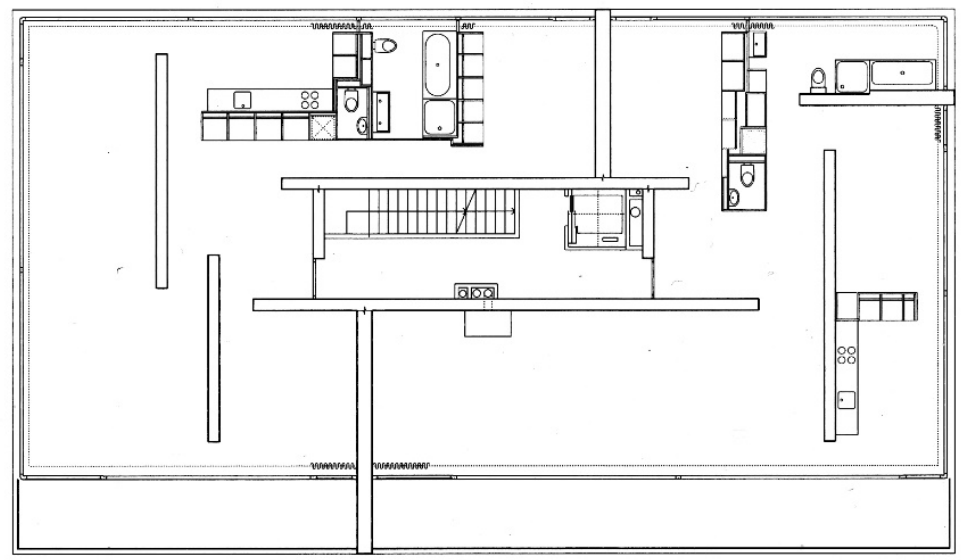

Planta segunda / Second floor plan

Fig. 9 Apartments on the Forsterstrasse, Zurich (1999-2003).

Source: Christian Kerez 2000-2009: Basics on Architecture, El Croquis 145 (2009). 


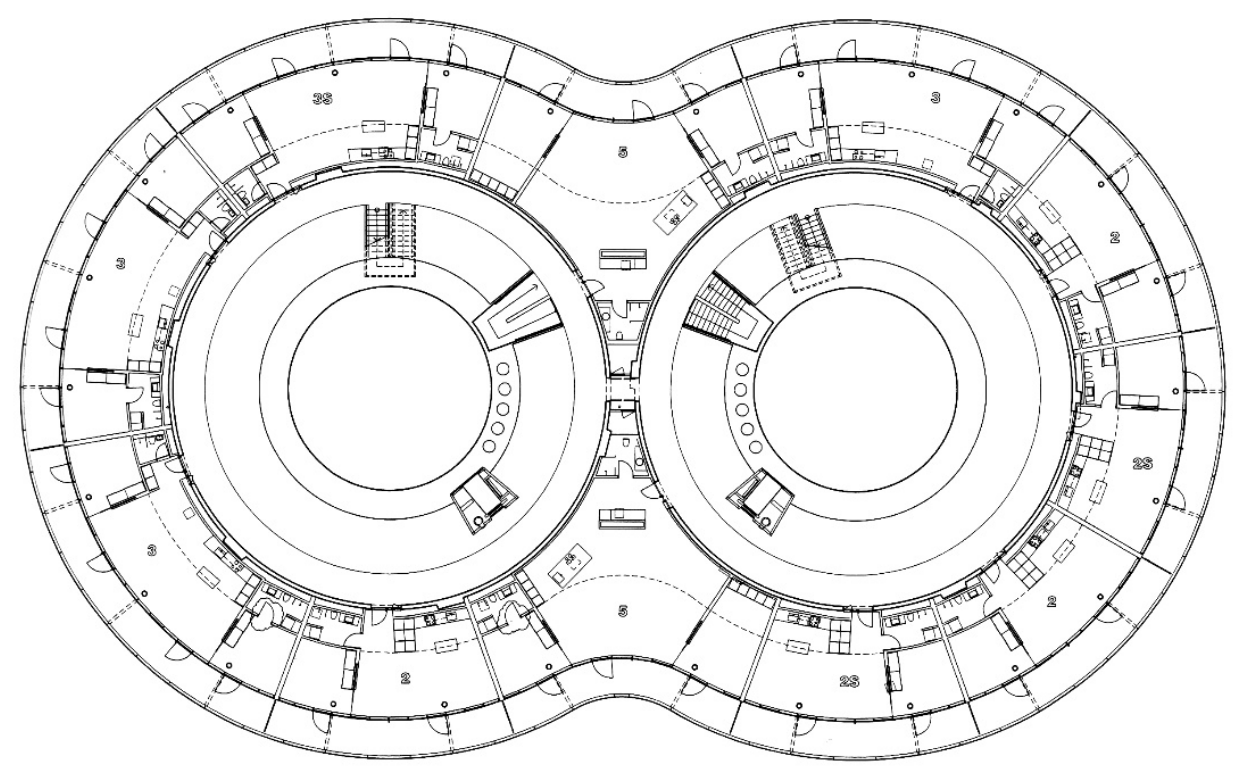

Fig. 10 MVRDV, Frøsilo, Copenhagen (5).

Source: Ilka and Andreas Ruby (eds. ), MVRDV: Buildings (Rotterdam: NAi 010 Publishers, 2015).
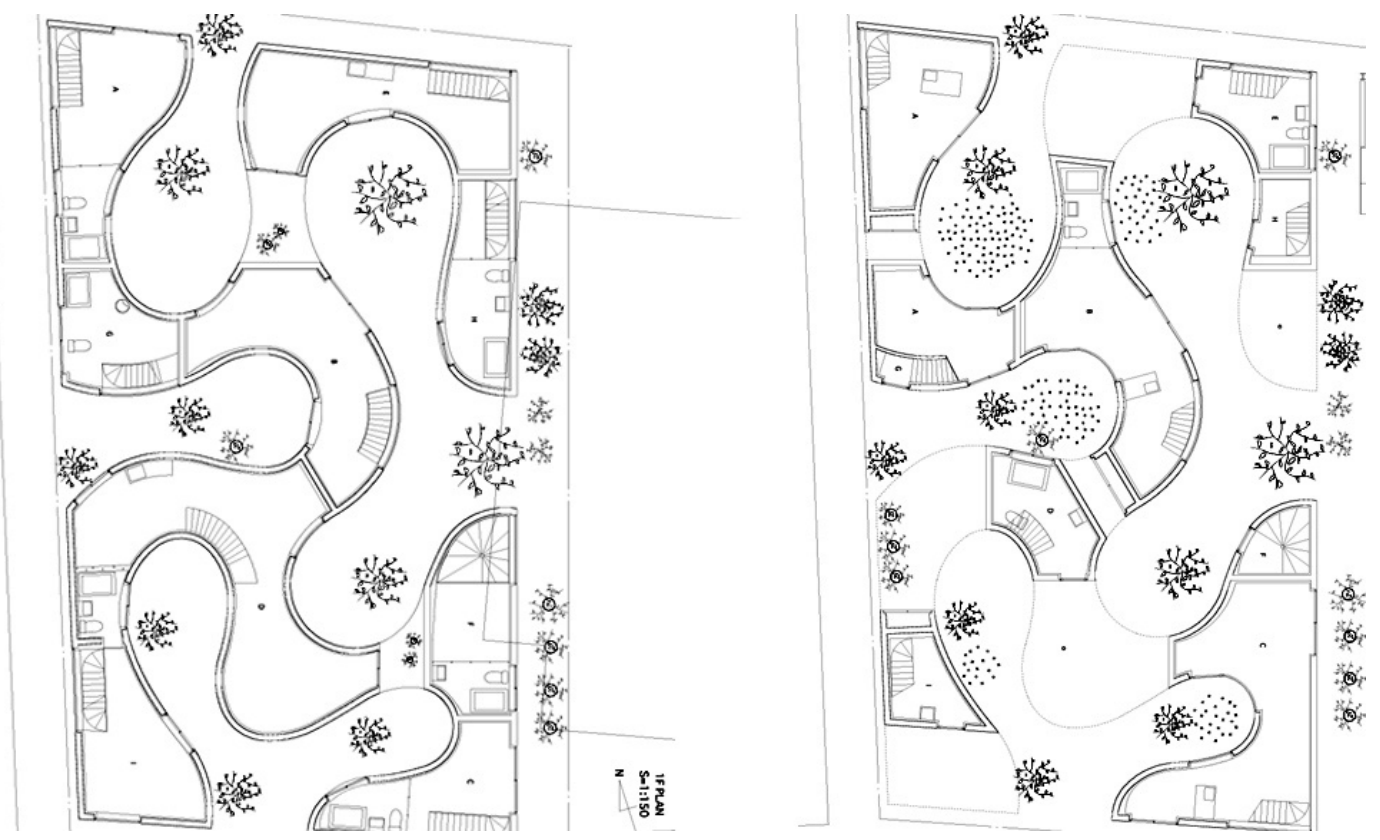

Fig. 11 Kazuyo Sejima Associates, Okurayama Apartments (2008).

Source: SANAA: Kazuyo Sejima \& Ryue Nishizawa, 2004-2008, El Croquis 139 (2008). 

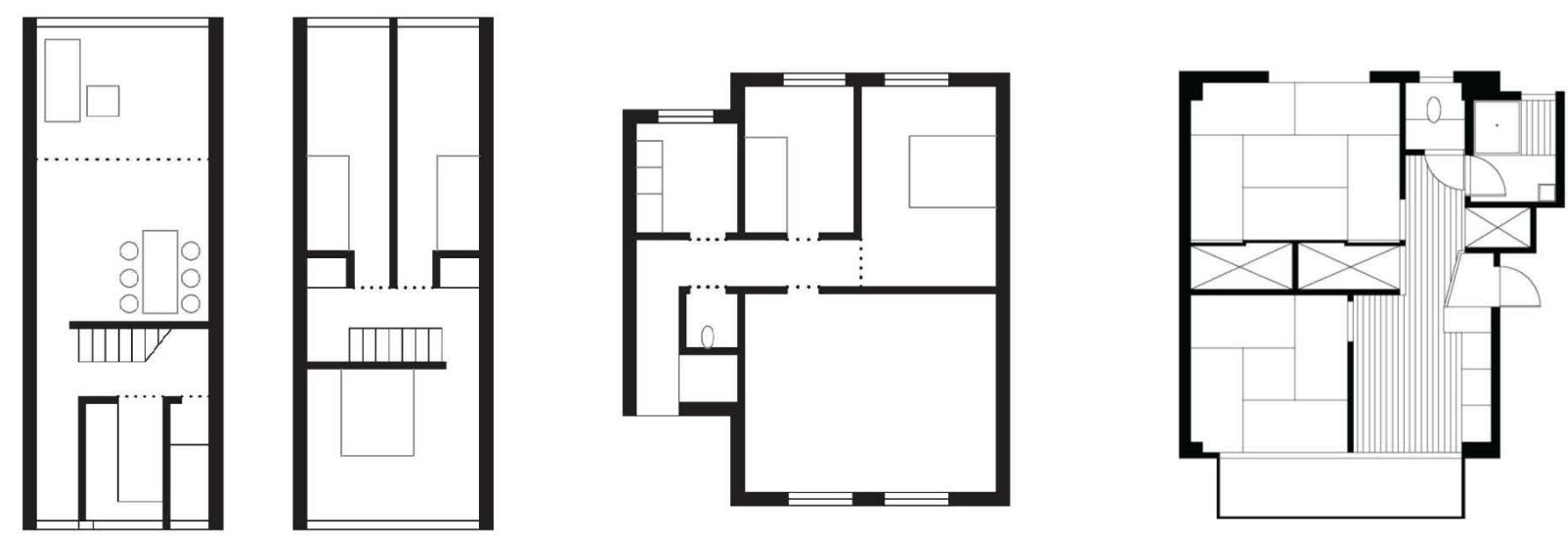

Fig. 12 Atelier 5, Siedlung Halen / Michel De Klerk, Eigen Haard Estate / Danchi apartment Redrawn by author. Danchi courtesy of E. Hanae Bliah.

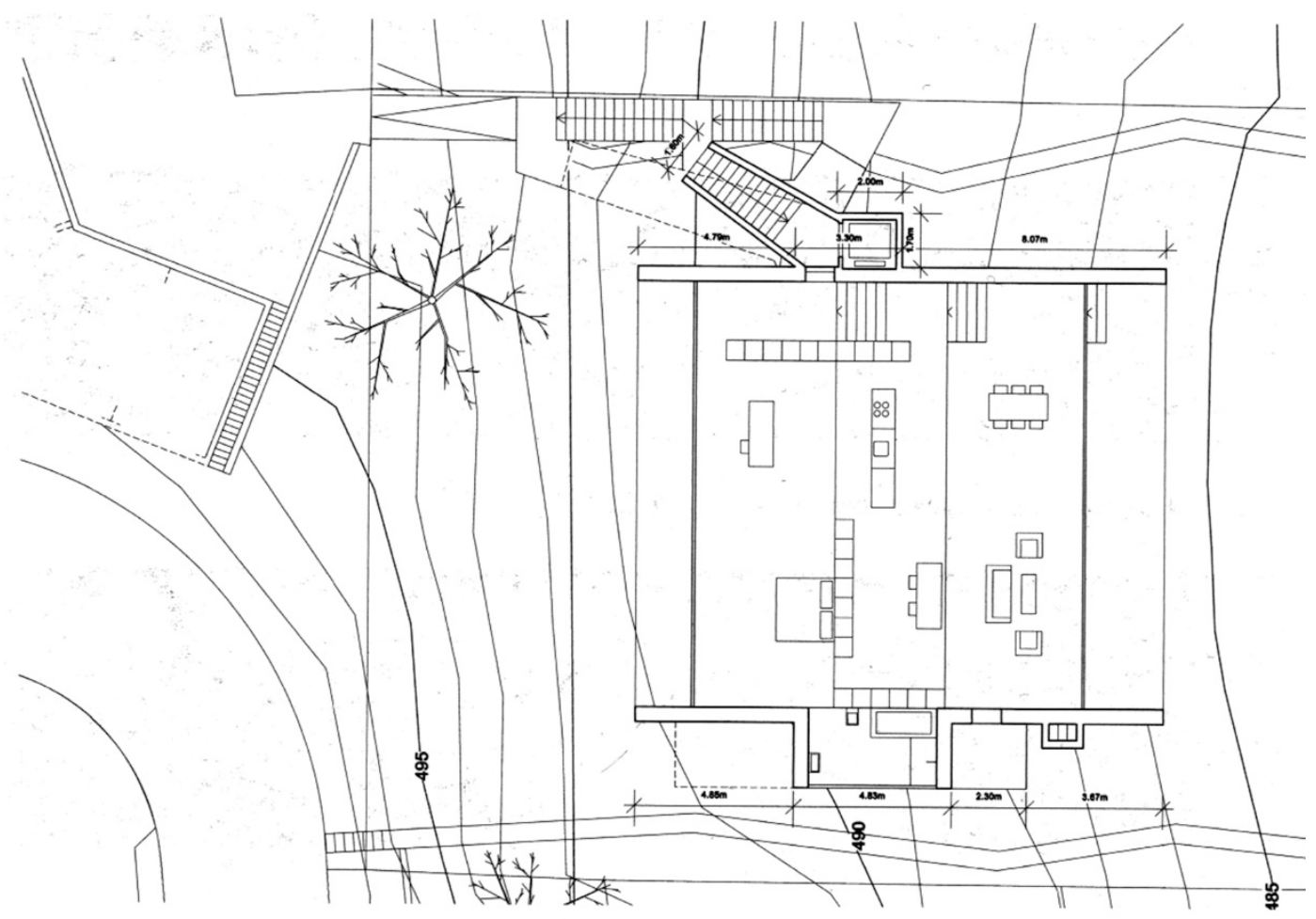

Fig. 13 Christian Kerez, Apartments with a Lake View (2005)

Source: Christian Kerez 2000-2009: Basics on Architecture, El Croquis 145 (2009). 

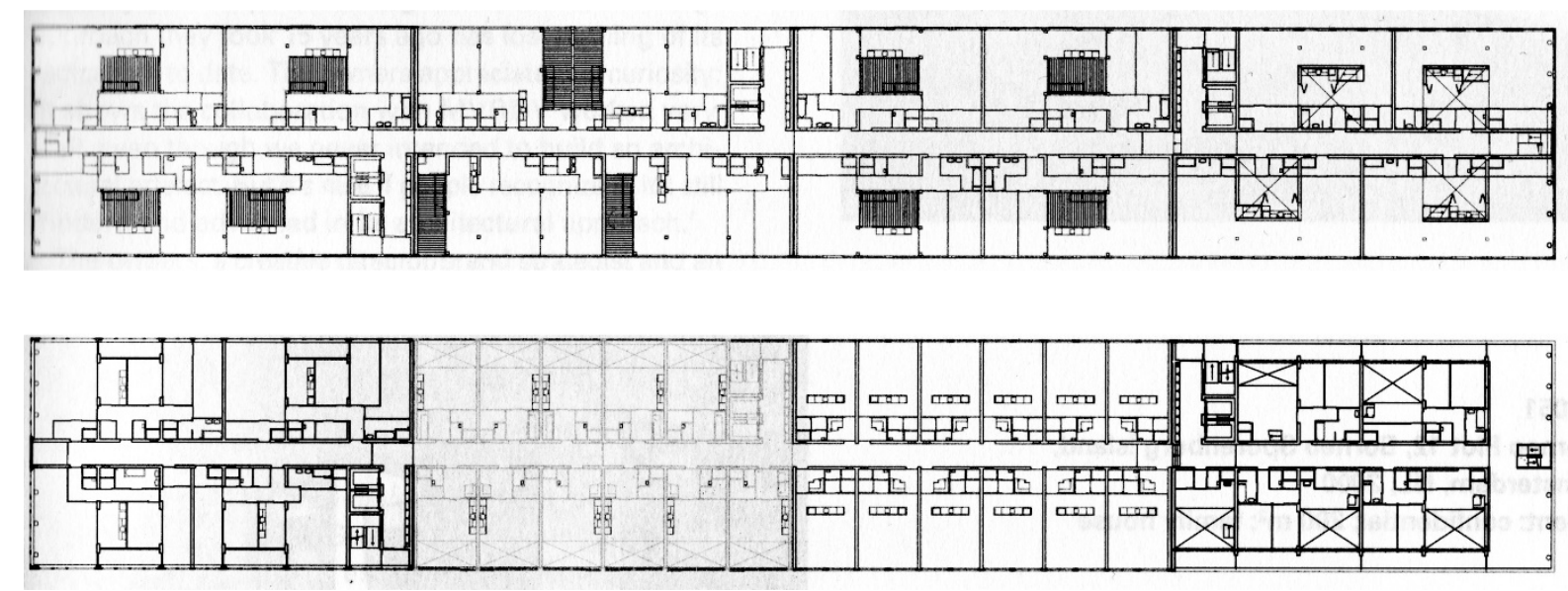

Fig. 14 MVRDV, Silodam, Amsterdam (2002)

Source: Ilka and Andreas Ruby (eds.), MVRDV: Buildings (Rotterdam: NAi 010 Publishers, 2015).
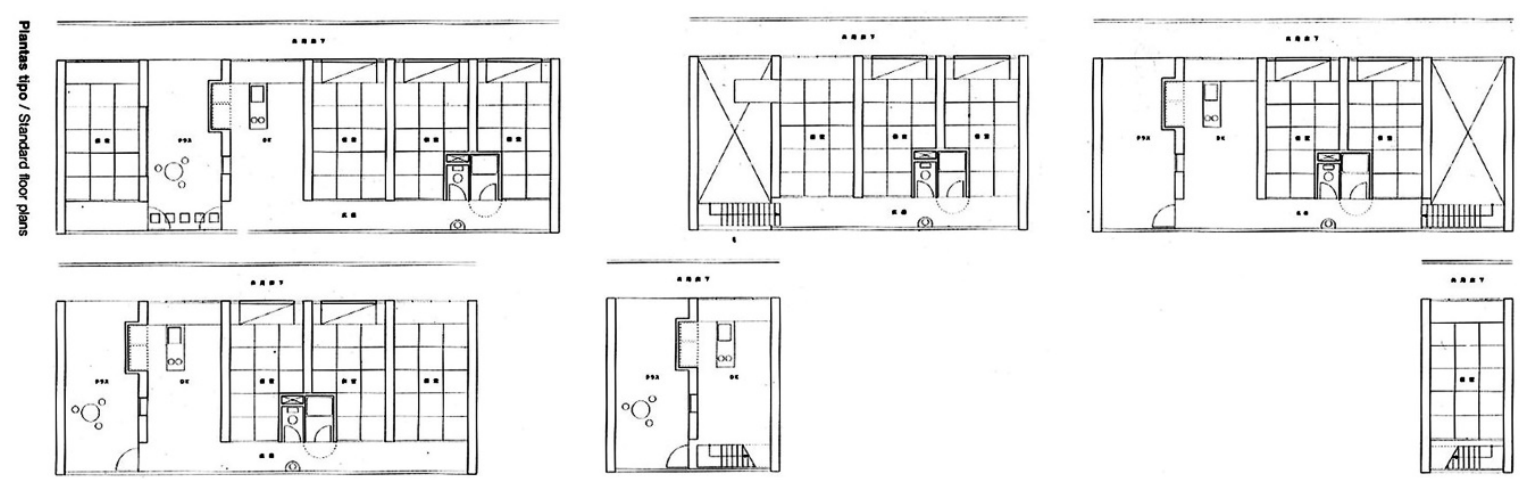

Fig. 15 Kazuyo Sejima, Gifu Kitagata Apartments (2000)

Source: Yuko Hasegawa, Kazuyo Sejima + Ryue Nishizawa: SANAA (Milan: Electa, 2006). 


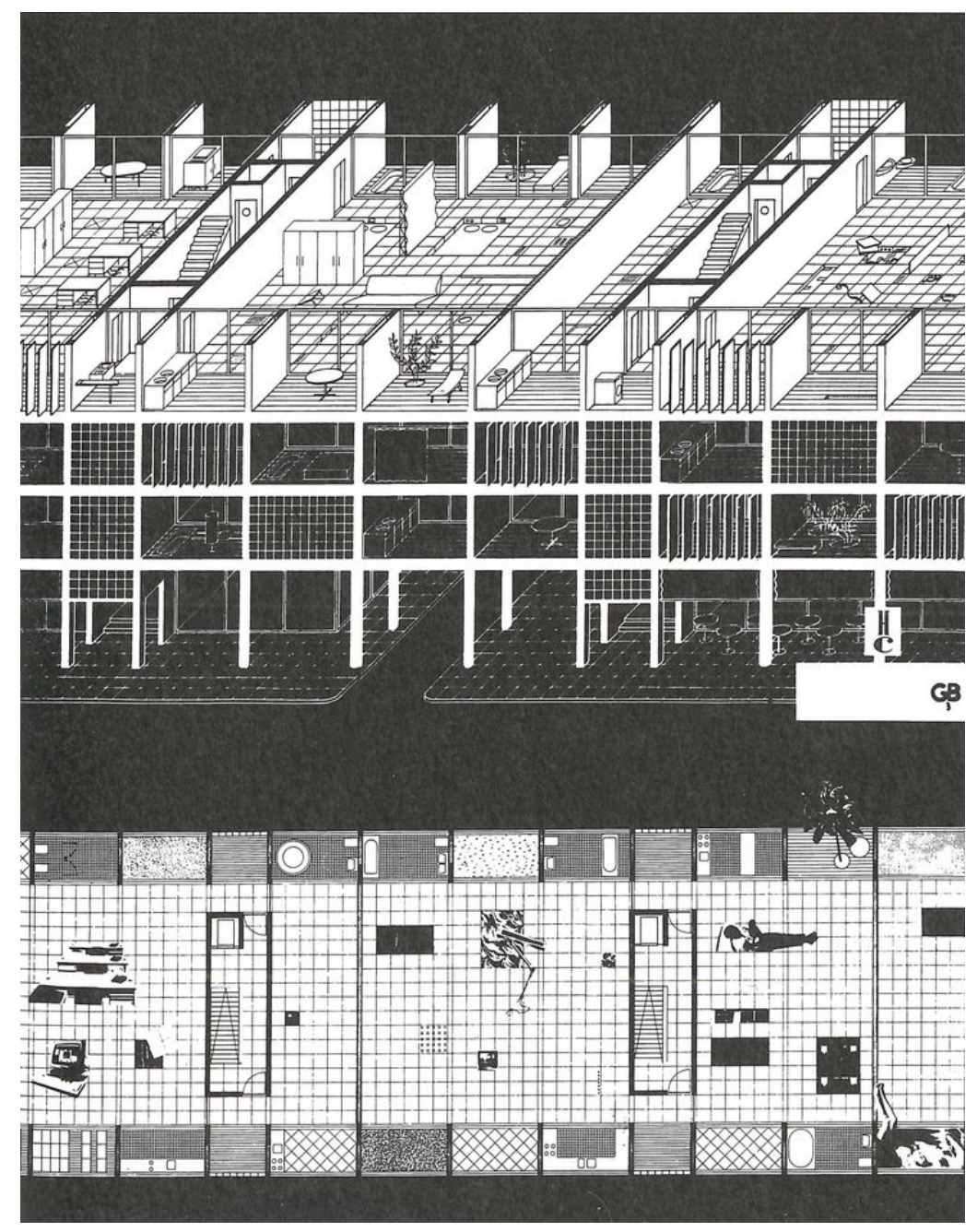

Fig. 16 Jan Neutelings, Alex Wall, Xaveer de Geyter, Housing Barcelona Competition (1992)

Source: Gustau Gili Galfetti, Pisos piloto: células domésticas experimentales (Barcelona: Editorial Gustavo Gili, 1997).
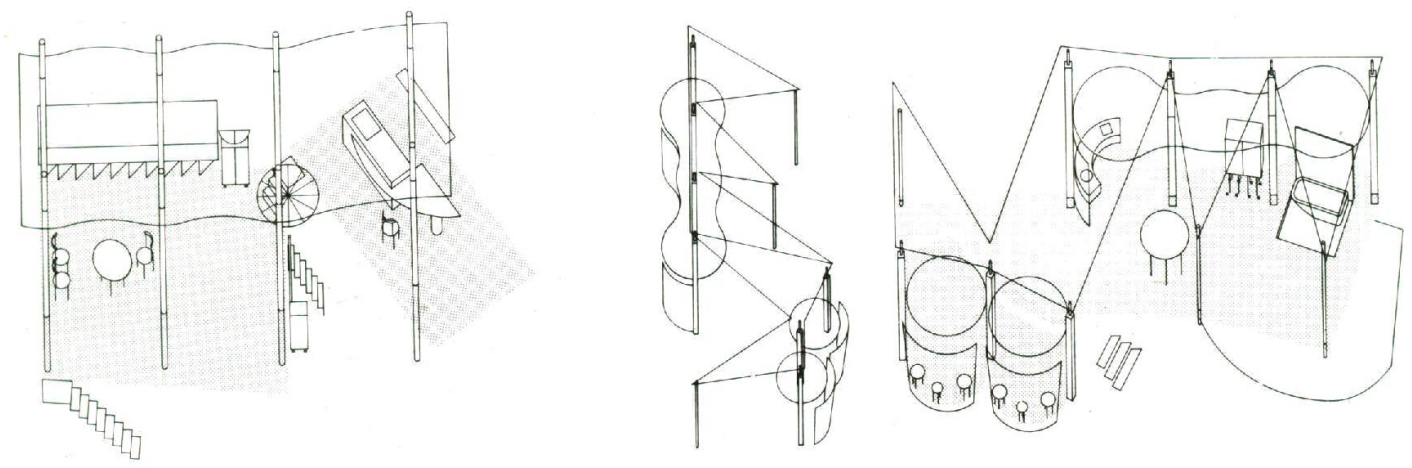

Fig. 17 Kazuyo Sejima, Schemes for Platform Houses (1987-1990) 
Source: Kazuyo Sejima + Ryue Nishizawa, El Croquis 77+99 (2001). 